\title{
Binocular Interactions in Accommodation Control: Effects of Anisometropic Stimuli
}

\author{
D. I. Flitcroft, S. J. Judge, and J. W. Morleya \\ University Laboratory of Physiology, Oxford OX1 3PT, United Kingdom
}

In binocular viewing of real targets, the accommodative demand in the two eyes is not in general identical, yet the accommodation response in the two eyes is equal. In order to investigate how the accommodative signals from the two eyes are combined, this study has examined the effects of several forms of dynamic anisometropic stimulation on the accommodation response in both man and the rhesus monkey (Macaca mulatta). All experiments were performed in a computer-controlled haploscopic apparatus to allow independent control of the accommodative stimuli to the two eyes and of the vergence stimulus. The vergence stimulus was held constant while the accommodation demand was modulated independently in each eye. Accommodation was monitored continuously with a dynamic infrared optometer. Four anisometropic conditions were used. In two of these conditions, accommodation demand was varied sinusoidally with time in both eyes, but with phases differing by $90^{\circ}$ or $180^{\circ}$ between the two eyes. In the two remaining conditions, accommodation demand in one eye varied sinusoidally, while the accommodation demand was constant in the other. In all cases, the form of the target pattern was identical in the two eyes.

The accommodation responses observed with these stimulus conditions were similar in both man and the monkey. When presented with conflicting stimuli in the two eyes, the accommodation response appeared to be best described as a compromise between the inputs to the two eyes; there were no indications of a purely random alternation of eye dominance of the form seen in binocular contour rivalry. When the accommodation demand was modulated in only one eye, there was a modulated accommodation response of similar phase to the control condition (i.e., both eyes modulated in phase) but with a much smaller gain (mean, $39 \%$ of control gain). When the accommodation demand was modulated in both eyes with a phase difference of $180^{\circ}$, no significant modulation was observed in the accommodation response at the stimulation frequency. When the interocular phase difference was $90^{\circ}$, a modulated response was observed that

\footnotetext{
Received Feb. 26, 1991 ; revised June 6, 1991; accepted Aug. 19, 1991.

This work was supported by Medical Research Council Programme Grant 7900491 to Colin Blakemore and by a Wellcome Trust major equipment grant. D.I.F. was supported by a Goodger Scholarship (Oxford University), and J.W.M. was supported by a Beit Memorial Rescarch Fellowship.

Correspondence should be addressed to Dr. S. J. Judge, University Laboratory of Physiology, Parks Road, Oxford OXI 3PT, UK.

- Present address: School of Physiology and Pharmacology, University of New South Wales, Kensington, NSW 2033, Australia.

Copyright (c) 1992 Society for Neuroscience $0270-6474 / 92 / 120188-16 \$ 05.00 / 0$
}

showed a mean phase lag $41^{\circ}$ more than that observed in the control condition (both eyes modulated in phase) and an appreciably smaller gain (mean, $55 \%$ of control gain). The extent to which the results can be described by a linear vector average of the uniocular inputs is considered.

When one eye is covered and a stimulus to accommodation is presented to the viewing eye, an equal response is generated in both eyes. This phenomenon, which is also observed in the pupillary light reflex, is termed consensuality. Several different aspects of accommodation control have been investigated for evidence of consensuality. Ball (1952) reported that in monocular viewing, accommodation in the nonviewing eye closely mirrored that of the viewing eye, a result that has been confirmed by studies such as those of Safra and Otto (1976), Hokoda and Ciuffreda (1982), and Thorn et al. (1983). Campbell (1960) reported that even the noise present in the accommodation responses of the two cyes is highly correlated, though only a single specimen trace was provided in evidence. Winn (1987) provided more quantitative evidence in support of this observation, reporting that the accommodative noise in the two eyes under static vicwing conditions was highly correlated up to $3.0 \mathrm{~Hz}$ or so. This constitutes strong evidence that the signals sent to the ciliary musculature of each eye are derived from a common source.

The existence of accurate accommodation in monocular viewing demonstrates that either eye can independently provide the information required to control accommodation. In binocular vicwing, two such sets of accommodative cucs exist, one from each eyc. The consensual nature of accommodation requires that the signals from each eye are at some point combined to generate a unitary accommodation response. The question of how the signals from the two eyes are combined is of importance in understanding not only the neural mechanisms and pathways that mediate accommodation under normal conditions, but also those situations where the two eyes are presented with conflicting accommodation demands. Unequal accommodation demands in the two eyes can arise when fixating an object located away from the midline and also in the situation where the two eyes are of different optical power, that is, in anisometropia.

At present there is little direct evidence as to either the location or the nature of this interaction. When faced with conflicting signals from the two eyes, the response may randomly alternate between following first one eye and then the other (as is the case in binocular contour rivalry). Alternatively, the final response may represent some form of averaging (cither linear or nonlinear) of the uniocular signals. Toates (1972), one of the few authors to raise the question directly, suggested that in the presence of anisometropia the final accommodation response 
constitutes a compromise between the two eyes, citing in support of this argument the finding that in anisometropes visual acuity can be higher in monocular viewing than in binocular viewing.

Only a handful of studies have directly considered the effects of anisometropia on the accommodation responses in binocular viewing. Stoddard and Morgan (1942) reported that anisometropia, induced by placing ophthalmic lenses in front of one eye during binocular viewing, produced a mean interocular difference in accommodation of only 0.15 diopter (D) for a $1 \mathrm{D}$ lens. Several studies have investigated the effects of the unequal accommodation stimulus that is presented to the two eyes in asymmetrical viewing. Rosenberg et al. (1953), using a crude subjective method to estimate accommodation (stigmatoscopy), claimed that in asymmetric viewing requiring up to $1.27 \mathrm{D}$ accommodative difference between the two eyes, the observed differences for one of the two subjects were as much $300 \%$ greater than the required differences! The following year Spencer and Wilson (1954), using identical apparatus, failed to replicate these unique findings, reporting that interocular differences were less than a few tenths of a diopter, a result in keeping with an earlier study by Ogle (1937).

The major failing of the above studies was that the lack of accurate and objective monitoring of the accommodation response prevented any firm conclusions being made about the nature of the combination of the uniocular signals, that is, whether the accommodation response was stable or unstable when conflicting demands were placed on the two eyes. Another weakness of these experiments was the use of static anisometropia. The difficulty with this technique is that the subject will experience not only a discrepancy between accommodation demands in the two eyes, but also a discrepancy between the mean accommodation and vergence demands, and this may cause "prism adaptation" (reviewed by Schor, 1983) that will affect the accommodation responses.

The method we chose avoided these difficulties by employing dynamic anisometropia. The time-averaged accommodation demand in each eye was equal and matched the vergence demand. What varied was the relative phase or amplitude of the stimuli in the two eyes. In these experiments, an attempt was made to characterize as fully as possible the nature of the binocular interactions in the primate accommodation system by examining, in both man and the rhesus monkey, the dynamic accommodation response (measured with an infrared optometer) under conditions where the two eyes are presented with dynamically modulated anisomctropic stimuli.

Some of these results have been presented in preliminary form elsewhere (Flitcroft, 1988; Flitcroft and Judge, 1989).

\section{Materials and Methods}

Subjects. Two adult rhesus monkeys (monkeys $\mathrm{B}$ and $\mathrm{M}$ ) and three human subjects (CMB, aged 22 years; DIF, aged 24; SJJ, aged 41) with normal oculomotor function served as subjects for these experiments. Appropriate refractive corrections were made for subjects SJJ and CMB to correct for naturally occurring refractive errors.

Animal preparation. The operant method of Wurtz (1969) was used to train the monkeys to fixate. The monkeys pressed a lever to switch on the fixation point. After an unpredictable interval of $0.5-4 \mathrm{sec}$, the fixation point dimmed slightly, and the monkeys were rewarded if they released the lever promptly. The animals worked for their daily fluid requirements but were given free access to fluid and fruit on $2 \mathrm{~d}$ each week. They were never worked for more than 6 weeks consecutively without a 1 week rest period.

Once trained on the Wurtz task, each animal was operated upon under barbiturate anesthesia in order to implant a head holder and subcon- junctival search coils (following the procedure described by Judge et al., 1980). Following surgery, the animals were given further training within the apparatus used for data collection. Both animals had had extensive experience (several months) of working within the apparatus prior to the collection of any of the data presented here.

The monkeys received positive reinforcement (in the form of a fluid reward) only for accurate fixation. No specific reinforcement was given on the basis of accommodative performance [unlike the reinforcement protocol of Cumming and Judge (1986), which did involve rewarding the animals on the basis of accommodative performance]. Similarly, the human observers were encouraged to avoid using voluntary effort to assist accommodation.

Measurement of accommodation. The accommodation responsc was continually monitored with a dynamic infrared optometer operating on the Scheiner principle (as used by Cumming and Judge, 1986). The rms noise level of the optometer was less than $0.1 \mathrm{D}$. As is generally the case with optometers, it was necessary to avoid motion or constriction of the real pupil interfering with the infrared light either coming into the eye or leaving it. This was achieved by three measures. First, the optometer incorporated an artificial pupil in the optical path receiving light reemitted from the eye. Second, the head was fixed (in the monkeys by means of the implanted head holder; in the human observers with deep dental bite bars). Third, the pupils of both eyes were dilated by instillation of a weak mydriatic solution ( 2 drops of a $2.5 \% \mathrm{w} / \mathrm{v}$ phenylephrine hydrochloride solution at least $30 \mathrm{~min}$ before the start of data collection). In principle, the optometer can be used without mydriatic, but this makes experimentation very tedious because the alignment of the optometer is then very critical, and data samples are much more likely to be spoiled by artifacts caused by pupil constriction or eye movements. A higher dosage of phenylephrine (10\%) has been reported to reduce the maximum amplitude of accommodation in the monkey (Chin et al., 1968), but Cumming and Judge (1986) found little evidence in monkeys (over the range of $1-5 \mathrm{D})$ that accommodation was significantly affected. Mordi et al. (1986) reported that $10 \%$ phenylephrine solutions can reduce the rate and magnitude of accommodation responses. Although these experiments were performed with only $2.5 \%$ phenylephrine, a dosage unlikely to have significant impact on the motor component of the accommodation system, the optical effects of pupil dilation will exert some influence on the accommodation control system through the effects on the ocular depth of focus. From human studies, it would appear that above $3 \mathrm{~mm}$, further increases in pupil diameter have little effect on the accommodation response (Hennessy et al., 1976). Nevertheless, in order to ensure a similar retinal image quality in the two eyes, phenylephrine was placed in both eyes. Furthermore, since the experiments described in this article are concerned primarily with the comparison of the performance of the accommodation system under different conditions rather than defining the absolute performance, the use of phenylephrine should not undermine the basic validity of the results obtained.

In the monkey experiments, the horizontal and vertical position of each eye was monitored with a magnetic search coil technique (Robinson, 1963; Fuchs and Robinson, 1966). Measurement of the position of the viewing eye allowed artifact-free accommodation samples to be reliably selected. Recording the horizontal positions of the two eyes allowed the measurement of the vergence angle of the eyes.

Stimulus presentation. These experiments were performed in a slightly modified version of the binocular haploscope described by Cumming and Judge (1986). This apparatus allowed independent control of both the accommodation demand for each eye and the vergence demand (Fig. 1). The right and left eye targets were presented by two independent Badal viewing systems, allowing the accommodative demand to be altered without any concomitant alterations in the angular size of the stimulus, thereby eliminating size change as a cue to accommodation (Kruger and Pola, 1985). The principal plane of the subject's eye was situated at the near focal point of the Badal lens, which had a power of $9 \mathrm{D}$. (Strictly speaking, the focal point should have been at the nodal plane of the eye, but the effect of this variation is small.) The targets were visualized via two front-silvered mirrors, alteration of the angle between these two mirrors allowing manipulation of the vergence stimulus. Since the centers of rotation of the mirrors were not coincident with the center of rotation of the eyes, the vergence stimulus was only approximately equal to the angle between the mirrors. Appropriate computer-controlled corrections were therefore made to ensure the accuracy of the vergence stimulus.

The use of a dynamic optometer that is able to provide continuous 


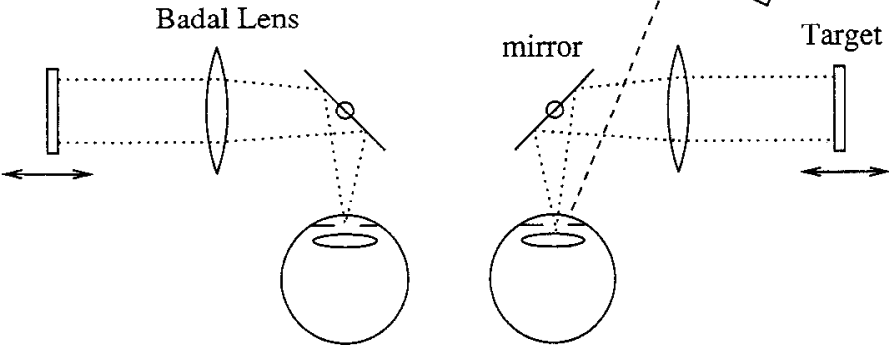

Figure 1. Schematic representation of the haploscope used to present accommodative stimuli to the two eyes. By rotating the two frontsilvered mirrors, the required vergence angle could be held constant while the accommodation demand was adjusted independently in the two eyes by altering the distance of the target from the Badal lens.

measurements of accommodation is clearly vital when attempting to examine the nature of the binocular interactions in accommodation. To overcome the problems associated with static anisometropia, the accommodation demand was dynamically modulated with a sinusoidal time course while the convergence angle was kept constant. A task that involves changes in accommodation while maintaining a fixed level of vergence in this manner is termed relative accommodation. Using this procedure, a variety of dynamic anisometropic conditions could be generated by independent alteration of the phase and gain of the accommodation stimulus presented to each eye. The temporal frequency of the stimuli presented to the two eyes was always the same, allowing the effects of any binocular interaction of the blur cues to be deduced by consideration of the gain and phase of the dynamic component of the accommodation response. The long time constant of prism adaptation makes it highly unlikely that this phenomenon could contribute in any way to the modulated component of the accommodation response at the temporal frequencies that were studied $(\geq 0.2 \mathrm{~Hz})$. Furthermore if the vergence stimulus is kept constant, then although vergence accommodation (Fincham and Walton, 1957) may serve to reduce the gain of the accommodation responses, it would be difficult to conceive how the phase of the modulated response could be altered. Nevertheless, in order to assess the impact of removing the effects of vergence cues (i.e., vergence accommodation), attempts were made to examine the effects of opening the vergence loop (i.e., removing foveal and parafoveal disparity cues to allow changes in vergence to occur without the normal feedback vergence response).

The target was moved in depth with a linear servo mechanism (Bryans and RS components), which was driven with a Cambridge Electronics CED 502 interface controlled by a PDP 11/34 computer. The vergence stimulus was also under computer control, the mirrors being mounted on two General Scanning galvanometers. In addition to controlling the accommodation stimulus, the computer was used to record digitized signals of the accommodation response, servo position, and eye position. The sinusoidal modulations used to control target position for the dy. namic accommodation task were derived from a Wavetek signal generator, with the computer modifying the gain and offset of its output to produce the required target movement.

All changes in vergence demand were achieved by rotating the left eye mirror, and as a result the right eye did not need to move during the tracking tasks. This ensured that the alignment of the optometer beam within the pupil of the right eye was not affected by changes in the vergence demand. Although the right eye will tend to move when vergence demand is rapidly modulated in asymmetric viewing, this was not a problem with the present experiments since the vergence demand was held constant and accommodative demand was modulated at relatively low temporal frequencies. The separation of the two mirrors (and Badal lenses) could be altered to take into account the different interocular separations of the subjects.

Form of the visual stimuli. In the experiments performed on the two monkeys, the visual target was a high-contrast spatially broad-band cross that subtended $20^{\circ}$ of visual angle. The central cross hairs subtended $3^{\prime}$ arc and were located within a circular fixation mark of $0.5^{\circ}$

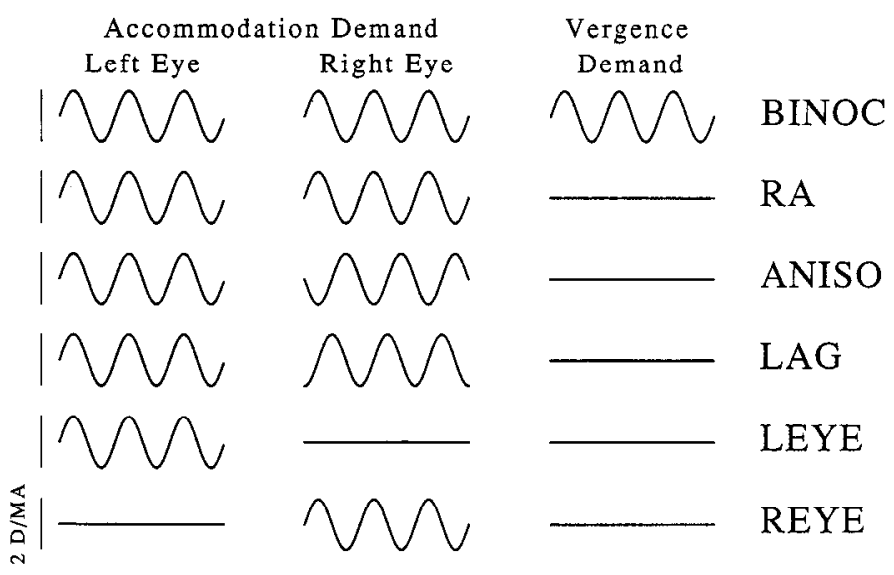

Figure 2. Diagram indicating the patterns of accommodation and vergence stimulation in the different viewing conditions. For each of the binocular viewing conditions, the temporal variation in the accommodation demand (first and second columns) is shown along with the vergence demand (third column). In all the anisometropic conditions (ANISO, LAG, REYE, and LEYE), the dioptric stimulus to accommodation was varied with a sinusoidal time course. In the LAG and ANISO conditions, the modulations in accommodation demand in the two eyes differed in phase by $90^{\circ}$ and $180^{\circ}$, respectively. In the LEYE and REYE conditions, the accommodation demand was modulated in one eye while being held static in the other eye.

in diameter. As well as using the cross target, the human subjects were also tested with another target that took the form of a high-contrast printed square-wave grating ( 1 cycle/degree). When the bars of the gratings were horizontal in each eye, the lack of vertical contours in the center of the visual field resulted in a partial opening of the vergence loop; however, it is still possible that the margins of the field of view may have provided crude fusional cues to peripheral vision.

Nature of accommodative tracking tasks. The flexibility of the haploscope used in these experiments allowed a variety of different combinations of accommodative and vergence tracking tasks to be investigated. A total of seven conditions were studied. Three of these represented control conditions (BINOC, MONOC, and RA), and in the remaining four (ANISO, LAG, LEYE, and REYE), a variety of dynamic anisometropic conditions were examined (Fig. 2). In the BINOC condition, the subject viewed with both eyes and the accommodation and vergence demands were modulated in unison so as to mimic a single target moving in depth (except for the fact that target size remained constant). The MONOC condition examined monocular accommodation tracking. In the RA (relative accommodation) condition, the subject viewed binocularly while the accommodation demand was varied in unison in the two eyes and the vergence demand was held constant.

It is important that in all the anisometropic tasks the vergence demand was kept fixed while the accommodation demand in each eye was varied independently. Thus, all the anisometropic conditions represented a form of relative accommodation. The different forms of anisometropia examined in this study are listed below.

1. ANISO: anisometropic relative accommodation in which the accommodation demand for cach cyc was modulated in counterphase, resulting in a dynamically modulated anisometropia.

2. LAG: anisometropic relative accommodation in which the phase of the sinusoidal modulation of accommodation in the two eyes differed by $90^{\circ}$, the right eye stimulus being lagged with respect to the left eye stimulus.

3. LEYE: anisometropic relative accommodation in which accommodation demand was modulated in the left eye alone. The accommodation stimulus in the right eye was equal to the mean level of the modulation presented to the left eye.

4. REYE: anisometropic relative accommodation in which accommodation demand was modulated in the right eye alone. The accommodation stimulus in the left eye was equal to the mean level of the modulation presented to the right eye.

In all these experiments, the amplitude and range of the modulations 

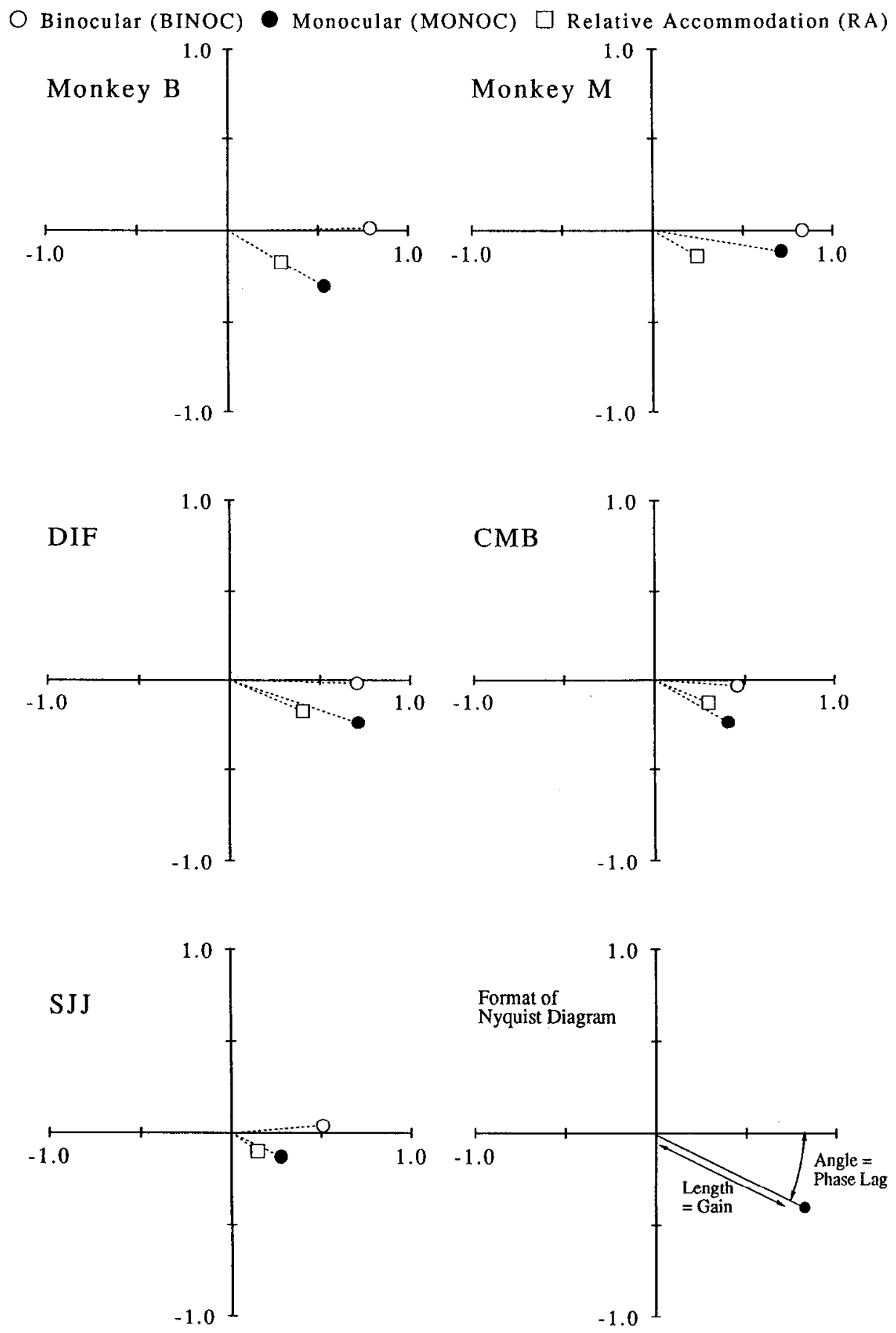

Figure 3. Mean gain and phase of the responses for each subject, both human and monkey, in the MONOC, BINOC, and RA conditions. Accommodation demand was modulated with a sinusoidal time course at $0.2 \mathrm{~Hz}$; the viewing target for all subjects was a high-contrast cross. The responses are represented in the form of a Nyquist diagram, a polar plot that allows both the gain and phase of a sinusoidal signal to be shown on a single graph. As indicated in the lower right panel, the gain is represented by the distance from the origin $(r)$ and the phase is represented by the angle between a line joining the point to the origin and the horizontal axis.

of accommodation demand were fixed, the targets being moved over a $2 \mathrm{D}$ range from either $1-3 \mathrm{D}$ or 2-4 $\mathrm{D}$ with a sinusoidal waveform. In the relative accommodation tasks (RA, ANISO, LAG, LEYE, and REYE), the vergence demand was not modulated and the static vergence level was appropriate for the mean accommodation demand. Small adjustments of \pm 0.5 meter angle (MA) ${ }^{1}$ were, however, made for the different observers in order to minimize problems of diplopia. At high temporal frequencies, there was a tendency for subjects to lose fusion and become grossly diplopic. As a result of this, most of the experiments were conducted at low temporal frequencies $(0.2-0.45 \mathrm{~Hz}$, though some data were collected at $0.6 \mathrm{~Hz}$ ).

${ }^{1}$ One meter angle corresponds to the angle between the optical axes of the eyes that is required to bring a target at $1 \mathrm{~m}$ into alignment on the foveae, i.e., $1 \mathrm{MA}$ $\simeq(\operatorname{IOS} \times 180) / \pi$ degrees, where IOS is the interocular separation in meters. The meter angle has the advantage over other possible units (such as degrees or prism diopters) that for a target requiring an accommodation response of $x \mathrm{D}$ the appropriate accommodative vergence response is $x$ MA.
Analysis of the accommodation response. The in-phase and quadrature components of each cycle of data were determined independently using standard mathematical procedures (Chatfield, 1984). Unbiased estimates of the mean gain and phase of the responses were derived from these components in the manner described in Cumming and Judge (1986). The transfer function of the electronic filtering on the optometer was taken into account in the calculation of the gain and phase of the response. An implicit correction was made for the dynamic performance of the accommodation servo itself since the gain and phase of the response were calculated with reference to the actual position of the target (as determined by the positional output of the servo).

The gain and phase of each cycle of data were normally calculated using the accommodative stimulus presented to the left eye as the reference signal; that is, the calculated gain is the ratio of the amplitude of the data to that of the reference signal, and the calculated phase is the phase difference between the data and the reference signal. The one exception to this was the REYE condition, in which the right eye stim- 


\section{Conditions:}

- Normal Rel. Accommodation

O VOL Rel. Accommodation

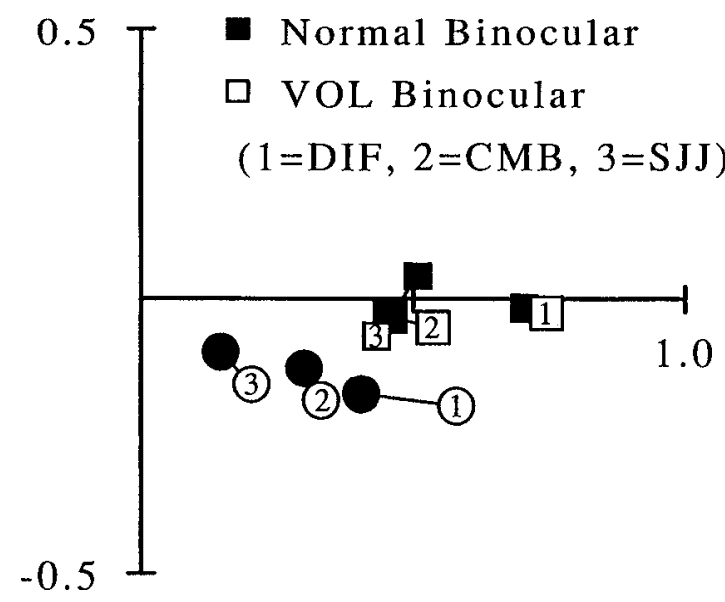

Figure 4. Detail of a Nyquist diagram showing the effects of removing foveal fusion cues (VOL, vergence open loop) on the accommodation responses of human subjects in the BINOC and RA conditions. The solid symbols represent the responses with the cross targets, and the open symbols represent the responses with the horizontal grating targets. The responses of the different subjects with the two forms of target are linked by lines. The responses of the different subjects are marked with the numbers 1 (DIF), 2 (CMB), and 3 (SJJ).

ulus served as the reference since the left eye stimulus was not modulated. In the ANISO condition, the sccond harmonic component of the accommodation response was also calculated. Since there was no second harmonic present in either of the sinusoidal modulations presented to either eye, the amplitude of any second harmonic component was expressed as a fraction of the amplitude of the fundamental frequency component of the stimulus.

\section{Results}

Since there have not, to our knowledge, been any previous reports of the gain and phase of relative accommodation during a dynamic tracking task in either man or the rhesus monkey, it is important to consider the characteristics of such responses under normal conditions before considering the effects of anisometropia.

\section{Comparison of relative accommodation with normal binocular and monocular viewing}

Figure 3 shows, in Nyquist diagram form, the mean values of the gain and phase of the accommodation response for each subject in the BINOC, MONOC, and RA conditions. All the data shown in this figure were obtained using the "cross" target (see Materials and Methods) with the accommodation demand sinusoidally modulated with an amplitude of 1 D (i.e., a $2 \mathrm{D}$ range, peak to peak) at a temporal frequency of $0.2 \mathrm{~Hz}$.

The most characteristic difference between monocular (MONOC condition) and binocular (BINOC condition) accommodation was the smaller phase lags of the responses in binocular viewing, though there were appreciable intersubject (not obviously species-dependent) differences in the magnitude of this decrease. Such an enhancement of the dynamic performance of accommodation on changing from monocular viewing to binocular viewing accords with the studies of monkey accommodation and vergence reported by Cumming and Judge (1986).
Less consistent changes were observed in the gains of the responses obtained in the MONOC and BINOC conditions; two subjects showed slightly larger gains (DIF, $p<0.05 ; \mathrm{CMB}, p$ $>0.2$, NS) in monocular viewing, whereas the others showed significantly larger gains in binocular viewing (monkey $\mathrm{B}$, monkey $\mathrm{M}$, and $\mathrm{SJJ}, p<0.001$ for all).

For all subjects, the gain of relative accommodation (RA condition) was significantly less $(p<0.001$ for each subject) than that of normal monocular (MONOC condition) accommodation. The ratio of the gain in the RA condition to that in MONOC condition for each subject was 0.59 (DIF), 0.69 (CMB), 0.58 (SJJ), 0.56 (monkey B), and 0.37 (monkey M). The phase lags of the accommodation responses showed much greater similarity in the MONOC and RA conditions than did the gains. Indeed, only monkey $M$ showed a statistically significant difference $(p<0.0001)$ between the phase lag present in monocular accommodation and relative accommodation, the phase lag increasing from $8.8^{\circ}(1.4 \mathrm{SE})$ to $28.8^{\circ}(1.1 \mathrm{SE})$. Although for this animal the phase lag in RA was similar to that in the other subjects, the phase lag of monocular accommodation in this animal was much lower than for the others. Subject CMB showed no significant difference between the phase lags in the MONOC and RA conditions with the cross target (Fig. 3), but with the grating target, the phase lag in the RA condition was significantly greater than that in the MONOC condition (see Table 1, Fig. 11).

Overall, there was no major difference between the two species in the pattern of responses obtained under normal binocular viewing (BINOC condition), under monocular viewing (MONOC condition), and during the relative accommodation task (RA condition).

\section{Opening the vergence loop: elimination of vertical contours in central field}

Elimination of vertical contours within the central visual field provides a simple means for removing the foveal vergence cues and therefore results in a partial opening of the vergence loop. In the experiments performed with the human subjects, this was achieved by presenting vertically modulated gratings (i.e., the bars of the gratings were horizontal) to each eye. With the monkeys this technique was not routinely used because fixation was much poorer with this form of target as compared with the cross target, resulting in unacceptable levels of eye-movement artifacts in the optometer recordings.

This method was far from perfect since the margin of the visual field (the target subtended $20^{\circ}$ and had a dark surround) could act as a cue to fusion. Although the accuracy of static vergence has been reported to decline with increasing eccentricity (Ogle et al., 1949), Francis and Owens (1983) have reported that vergence responses can still be elicited with stimuli $8^{\circ}$ from the fovea. The impact of this simple manipulation of the visual stimulus on the gain of relative accommodation in man is shown in Figure 4. In all three cases, the gain of relative accommodation was higher with the grating targets than with the normal cross targets, and the phase of the responses was little changed.

The contributions made by peripheral fusional cues were most apparent (i.e., the effect of opening the vergence loop is smallest) in the BINOC condition (normal binocular viewing). The reduction of the phase lag of accommodation when blur cues are supplemented with disparity cues (via the vergence-accommodation cross-link) in normal binocular viewing was still par- 
CMB $0.2 \mathrm{~Hz}$ ANISO

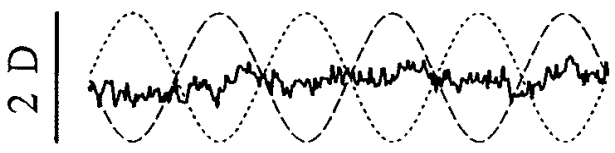

CMB $0.2 \mathrm{~Hz}$ RA

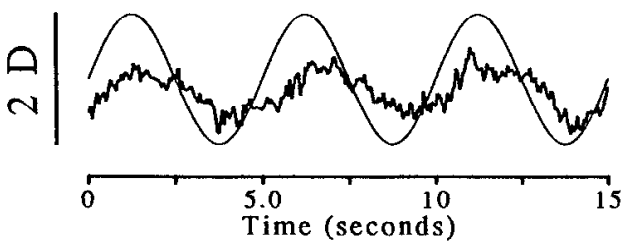

Time (seconds)
DIF $0.2 \mathrm{~Hz}$ ANISO

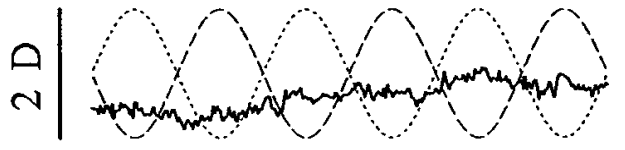

DIF $0.2 \mathrm{~Hz}$ RA

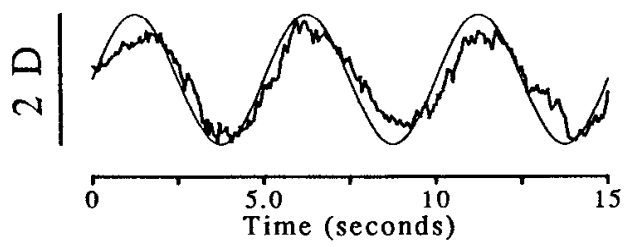

Monkey M $0.2 \mathrm{~Hz}$ ANISO

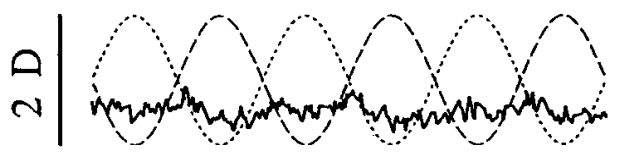

Monkey M $0.2 \mathrm{~Hz}$ RA

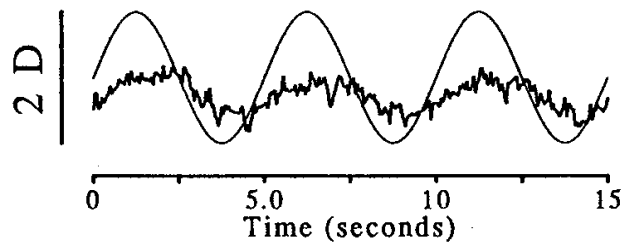

Figure 5. Examples of the accommodation responses of $\mathrm{CMB}, \mathrm{DIF}$ monkey $\mathrm{M}$, and monkey $\mathrm{B}$ in counterphase anisometropia (the ANISO condition). The accommodation response observed in non-anisometropic relative accommodation (the RA condition) is included for comparison. Dashed lines, right eye stimulus; dotted lines, left eye stimulus. In the RA examples, the right and left eye stimuli are denoted by a solid line. tially in evidence with the grating targets (Fig. 4). This indicates that foveal disparity cues are not essential for the dynamic control of vergence accommodation. Indeed, the effects of eliminating foveal cues upon the dynamic performance of vergence accommodation indicate that in dynamic vergence tasks fusion cues up to $10^{\circ}$ from the fovea are able to support dynamic responses that are almost as accurate as those in the presence of foveal fusional cues.

\section{Accommodation responses with anisometropic stimuli}

In the four anisometropic conditions (ANISO, LAG, LEYE, and REYE; see Fig. 2), the accommodation responses represented a form of relative accommodation since the vergence stimulus was kept constant throughout. In order to maximize the gain of the accommodation responses, the human data described below were collected with the grating targets (except where explicitly stated to the contrary). Even with the grating target, the gain of relative accommodation in subject SJJ (aged 41 years) was so low (possibly due to incipient presbyopia) that this subject was not extensively investigated under anisometropic conditions. The cross targets were used for the monkey experiments due to the poor fixation observed when the grating targets were used with the monkeys.

\section{Counterphase anisometropia}

Under dynamic anisometropia (ANISO condition), the consensual accommodation response showed essentially no consistent modulation at the stimulus frequency (Fig. 5). There was little indication of any "accommodative rivalry"; the response did not appear to flip randomly from following first one and then the other eye as is observed perceptually with conflicting contours (Breese, 1909). Monkey B did, however, appear to follow systematically the lower (in dioptric terms) of the two accommodative stimuli. Nyquist diagrams of the gains and phases of individual cycles are shown in Figure 6 . The responses can be seen to be clustered around the origin in the Nyquist diagram. This distribution indicates that the gains of the individual cycles were very small and that there was no consistent phase relationship between the accommodation responses and stimuli presented to the two eyes.

When the images from two objects, located at different distances, are superimposed upon the retina, it has been suggested that the eye tends to accommodate on the object requiring least accommodative "effort," that is, the object that is nearest to the distance of the resting focus (the Mandelbaum effect; Mandelbaum, 1960; Owens, 1979). This suggests that when faced with anisometropic, counterphase modulation, accommodation may follow whichever stimulus is nearest to the resting level at any given moment. If the resting focus of the eye (in humans the resting focus has a mean value of approximately $1.5 \mathrm{D}$; Leibowitz and Owens, 1978) was not encompassed in the range over which the accommodation demand was modulated, then one might predict that the response would follow whichever eye was presented with the stimulus nearer to the resting focus. This would result in the accommodation response approximating the rectified waveform shown in Figure $7 a$ (waveform 2).

As shown in Figure $7 b$, the amplitude spectrum of waveform 2 is dominated by a second harmonic component $(2 \omega)$ and there 

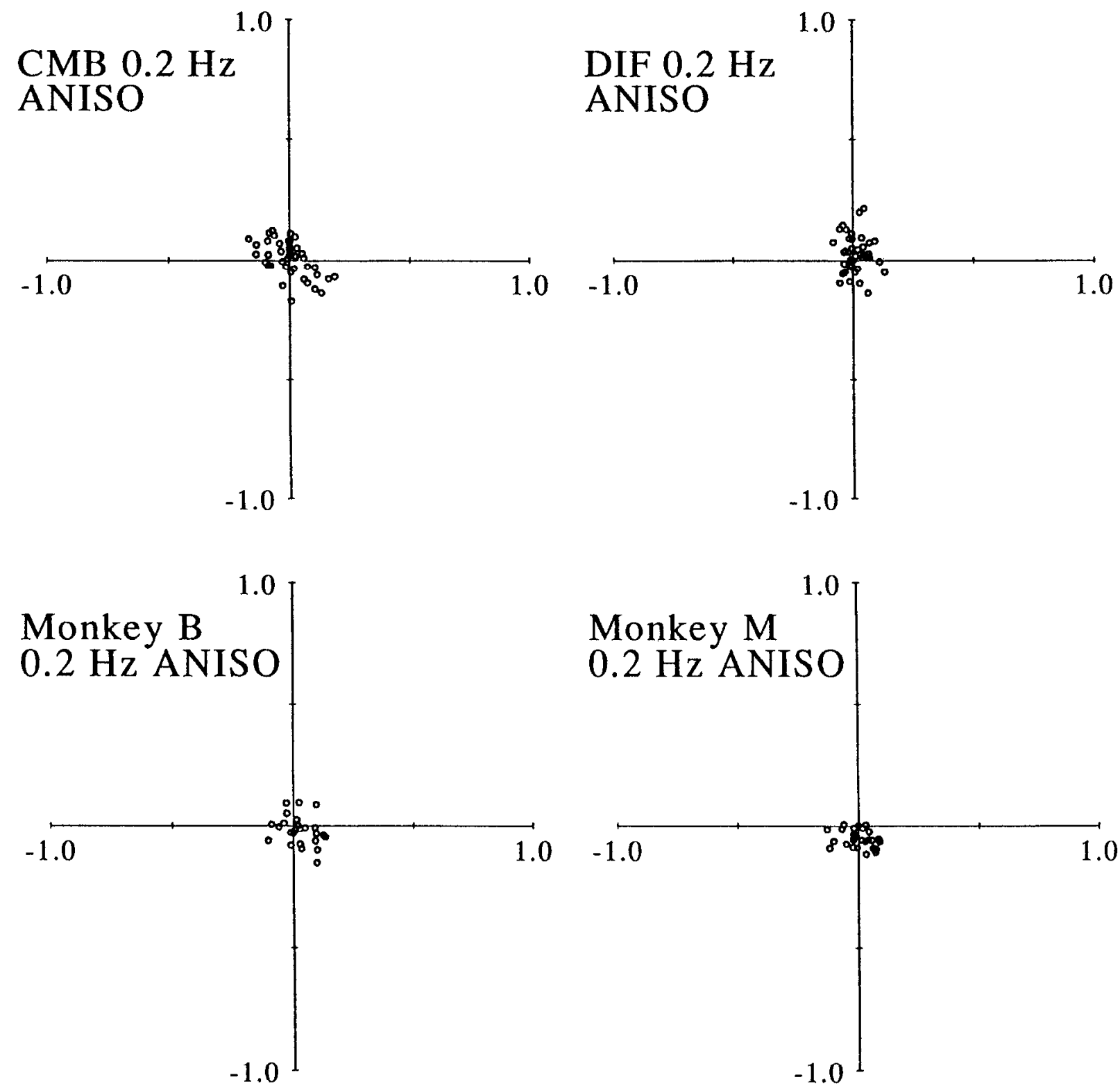

Figure 6. Scatter plots showing (on a Nyquist diagram) the gain and phase of individual responses in the ANISO condition for subjects CMB, DIF, monkey $\mathrm{B}$, and monkey $\mathrm{M}$.

is no component at the modulation frequency. If, as in Figure $7 b$, the amplitude of the sinusoidal modulations of accommodation demand is set to unity, then the amplitude of this second harmonic component is 0.424 .

In the majority of the responses to anisometropic stimulation there was no obvious second harmonic component, though it appeared to be a feature of at least some of the responses. A small second harmonic component was particularly noticeable in the responses of monkey B. Figure $8 a$ shows the amplitude of the first and second harmonic components of individual cycles responses of monkey $B$ in the ANISO and RA conditions at $0.2 \mathrm{~Hz}$ and $0.45 \mathrm{~Hz}$. At $0.2 \mathrm{~Hz}$, the distributions of the responses in the RA and ANISO conditions are quite distinct, the ANISO responses showing both a smaller fundamental component and a larger second harmonic component. The responses at $0.45 \mathrm{~Hz}$ are less clustered and less distinct. At this higher frequency, there is only a small difference between the amplitude of the second harmonic in ANISO as compared with the RA condition, but as was the case at $0.2 \mathrm{~Hz}$, the fundamental component is smaller in the ANISO condition than in the RA condition at $0.45 \mathrm{~Hz}$.

If the second harmonic component were simply noise, then one would not expect any consistent relationship between the phase of the second harmonic and the stimulus. Figure $8 b$ shows both the gain and phase of the second harmonic component of the responses obtaincd in the RA and ANISO conditions. At 0.2 and $0.45 \mathrm{~Hz}$, the phase lag of the second harmonic component in the ANISO condition shows a degree of consistency that is absent in the RA condition. Calculating the vector average of the second harmonic response reveals a significant difference between the gain in the RA and ANISO conditions at both $0.2 \mathrm{~Hz}$ [RA, $0.024 \pm 0.009( \pm$ SE); ANISO, $0.110 \pm 0.008]$ 
and $0.45 \mathrm{~Hz}(\mathrm{RA}, 0.055 \pm 0.007$; ANISO, $0.100 \pm 0.009)$. This second harmonic component is present at both 0.2 and 0.45 $\mathrm{Hz}$, indicating that it is not simply the result of a tendency of the accommodation system to fluctuate at or near $0.4 \mathrm{~Hz}$.

\section{The LEYE and REYE conditions}

In the LEYE and REYE conditions, the accommodation demand for one eye was modulated while the accommodation demand in the other eye was kept constant. The major feature of the accommodation responses observed in this condition was their low gain (Fig. 9). The gains of the accommodation response in the LEYE and REYE conditions were generally less than half of those observed in relative accommodation (RA condition). The results obtained with this pattern of stimulation are summarized in Table 1 and shown in Figure 10. Although the responses in these two conditions were similar, there were certain subject-specific differences in both the gain and the phase of the responses.

For DIF and monkey $\mathrm{B}$, the phase of the observed responses was similar in the REYE and LEYE conditions but there were differences in the gain of the responses (DIF displayed a higher gain in the REYE condition, whereas in monkey $B$ the gain was highest in the LEYE condition). With CMB and monkey $M$, the major difference between the REYE and LEYE conditions was observed in the phase of the responses (in both cases the phase lag was smaller in the REYE condition), with the gains being rather similar. It should be noted, however, that the statistical confidence limits on the phase measurements of monkey $M$ in the LEYE and REYE conditions were large (see Table 1). The variability in the phase of the accommodation response reflects the very small gains of the accommodation responses in these two conditions.

\section{The LAG condition}

In the LAG condition, there was a $90^{\circ}$ phase difference between the modulations of accommodation demand presented to the two eyes (the left stimulus was "leading"). Although the responses in this condition showed a consistent modulation at the fundamental frequency, this modulated component was less clearly sinusoidal than the responses obtained in the RA or MONOC condition (Fig. 11). In the LAG condition, the gains of the responses were smaller and the observed phase lags (measured from the left eye stimulus) were larger than those observed in the RA condition (see Table 1, Fig. 11). The increase in phase lag of the responses as compared with the RA condition varied from $24^{\circ}(\mathrm{CMB})$ to $64^{\circ}$ (DIF), with a mean for the four subjects of $40.9^{\circ}( \pm 8.46)$.

\section{Summary of results with anisometropia}

Figure 10 shows the results obtained at $0.2 \mathrm{~Hz}$ in the seven conditions examined for subjects DIF, CMB, monkey $\mathrm{B}$, and monkey $M$ (see also Table 1). The results for subjects DIF and $\mathrm{CMB}$ were obtained with the grating stimuli. The results for the monkeys were obtained with the cross target with the vergence loop closed. Despite the variation between the responses of the different subjects in each condition, the overall pattern of the results in the seven conditions is similar in the four subjects. The phase lag of binocular responses was less than that of monocular responses. The phase of the responses in all the binocular conditions except LAG was similar, with gains decreasing in the order MONOC, RA, LEYE or REYE, and ANISO. The phase a

Waveform 1

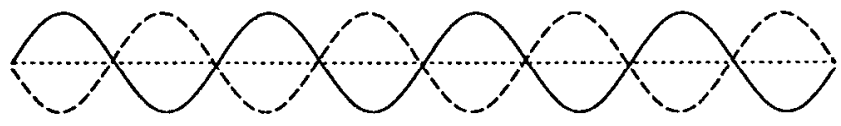

Waveform 2

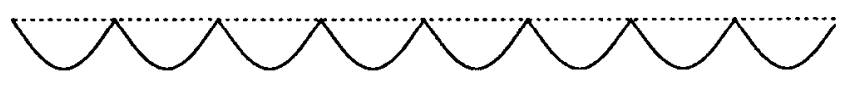

b

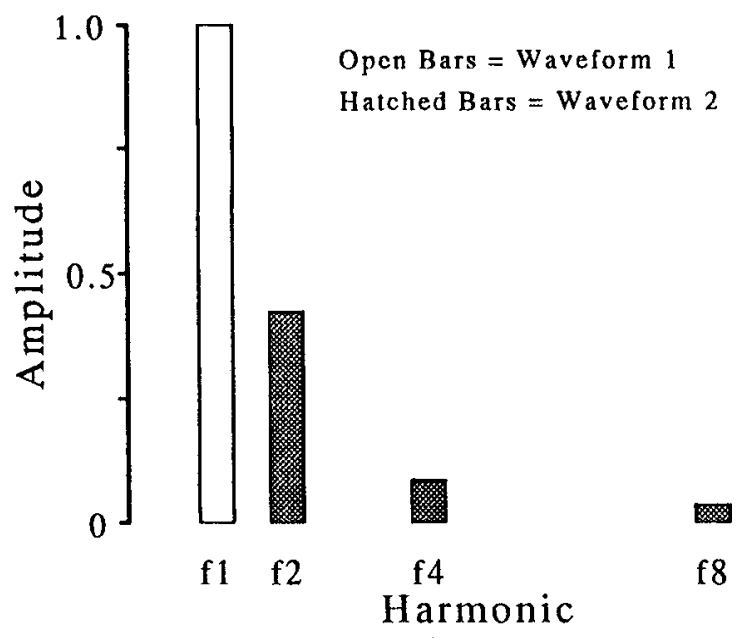

Figure 7. a, Waveform 1 shows two counterphase sinusoidal modulations of the form used in counterphase anisometropic stimulation (ANISO condition). Waveform 2 shows the signal that would result if accommodation always followed the eye that required the smallest accommodation response in the ANISO stimulus condition. $b$, Harmonic composition of the sinusoidal and rectified waveforms shown in $a$.

of LAG was approximately $45^{\circ}$ lagged behind that in other binocular conditions. Furthermore, although only four subjects were studied in detail, there does not appear to be much difference between man and the rhesus monkey. Indeed, of the four subjects the most striking similarities are between DIF and monkey $\mathrm{B}$, and between $\mathrm{CMB}$ and monkey $\mathrm{M}$.

The results presented above were obtained under conditions where the accommodation demand was modulated at a temporal frequency of $0.2 \mathrm{~Hz}$. Data were also obtained at other temporal frequencies between 0.1 and $0.6 \mathrm{~Hz}$. Altering the temporal frequency did not appear to alter substantially the overall patterns of responsiveness that were observed at $0.2 \mathrm{~Hz}$. As an example, Figure 12 shows the mean responses of monkey $B$ in all stimulation conditions at $0.2 \mathrm{~Hz}$ and $0.45 \mathrm{~Hz}$. Increasing the temporal frequency resulted in a reduction in the gain and an increase in the phase lag of all the anisometropic responses (except in the ANISO condition).

\section{Discussion}

\section{Consensuality of accommodation}

It has been assumed in these experiments that accommodation is truly consensual. In this study, accommodation was measured in only a single eye (in this case, the right), so it was not possible 
a
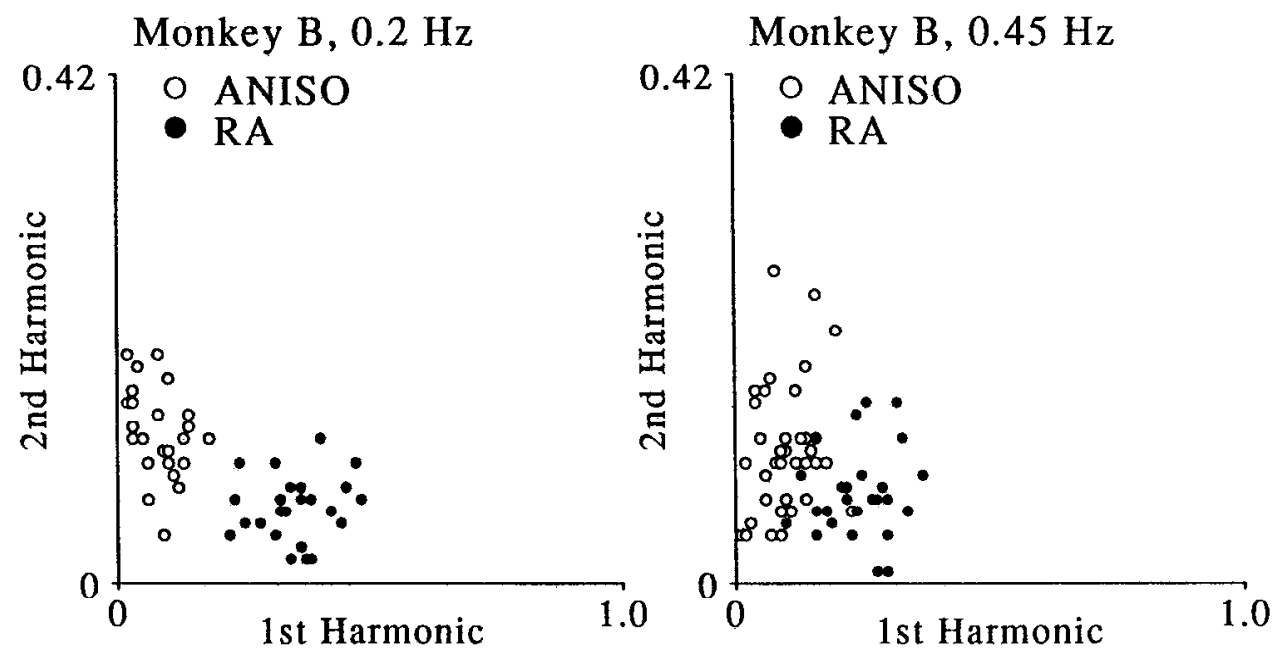

b
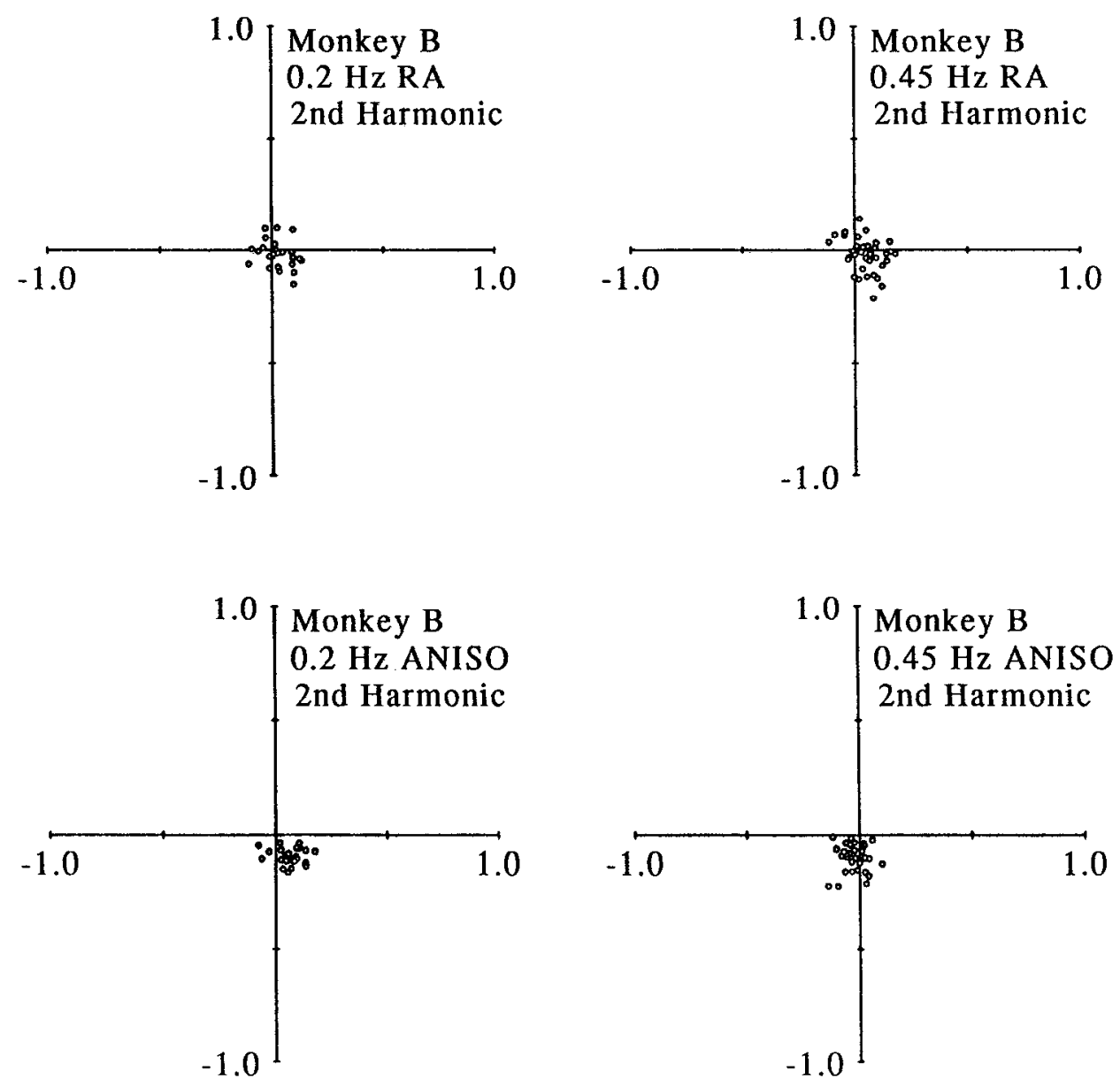

Figure 8. a, Scatter plot showing the first and second harmonic components of the accommodation responses (cycle by cycle) of monkey $B$ at $0.2 \mathrm{~Hz}$ and $0.45 \mathrm{~Hz}$ in the RA and ANISO conditions. $b$, Nyquist diagrams showing the distribution of the gain and phase of the second harmonic components of the responses of monkey $B$ in the RA and ANISO conditions at $0.2 \mathrm{~Hz}$ and $0.45 \mathrm{~Hz}$.

to test the validity of this assumption directly. Nevertheless the results obtained are fully consistent with the accepted doctrine that the innervation to accommodation in the two eyes is derived from a common source (Ball, 1952; Campbell, 1960; Safra and Otto, 1976; Hokoda and Ciuffreda, 1982; Thorn et al., 1983; Winn, 1987). Under conditions where accommodation demand was modulated in only one eye (i.e., the LEYE and REYE conditions), the accommodation responses in the right eye were similar irrespective of which eye was exposed to the varying accommodation stimulus. Furthermore, the lack of any significant accommodation response at the fundamental frequency of the accommodation stimulus during counterphase aniso- 
CMB $0.2 \mathrm{~Hz}$ LEYE

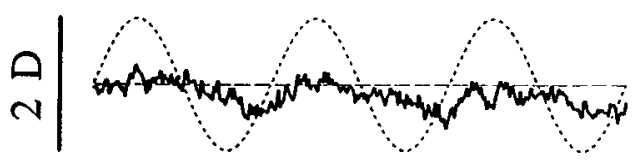

CMB $0.2 \mathrm{~Hz}$ REYE

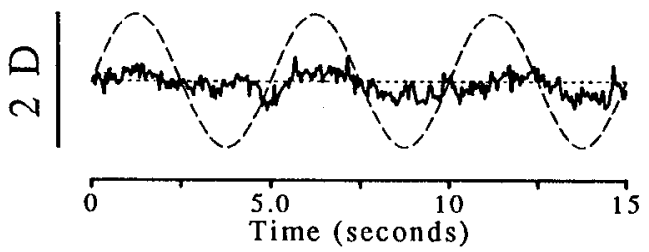

Monkey B $0.2 \mathrm{~Hz}$ LEYE

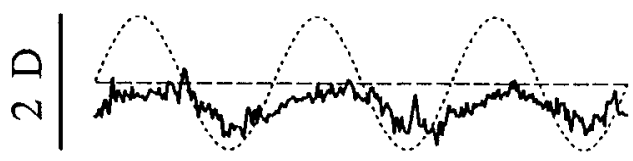

Monkey B $0.2 \mathrm{~Hz}$ REYE

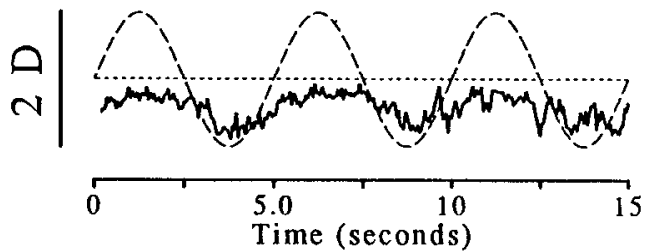

DIF $0.2 \mathrm{~Hz}$ LEYE

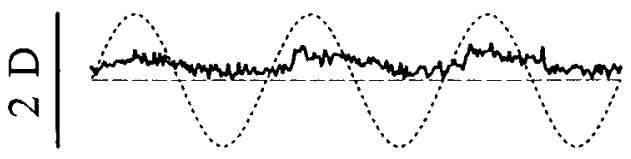

DIF $0.2 \mathrm{~Hz}$ REYE

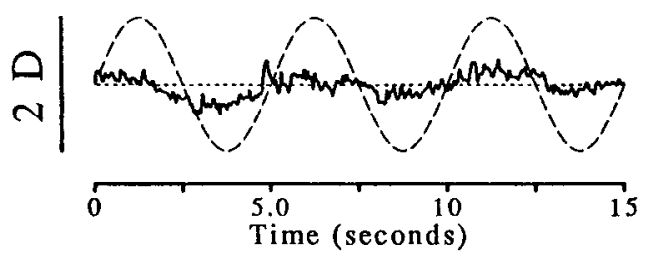

Monkey M $0.2 \mathrm{~Hz}$ LEYE

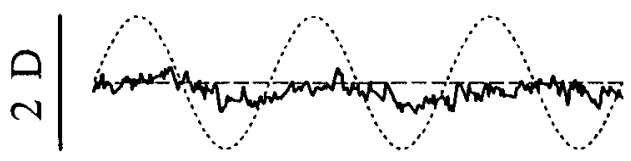

Monkey M $0.2 \mathrm{~Hz}$ REYE

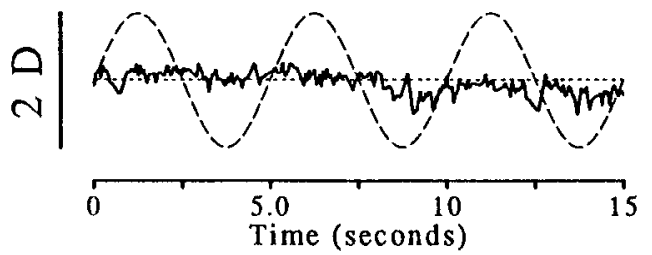

Figure 9. Examples of the accommodation responses of $\mathrm{CMB}$, DIF, monkey $M$, and monkey $B$ in the LEYE and REYE conditions (dashed lines, right eye stimulus; dotted lines, left eye stimulus). metropia (ANISO condition) counts against the idea that the accommodation response in each eye is under independent control. In the LAG condition, the phase of the accommodation responses was increased to values intermediate between the phase lags expected for the stimuli presented to each eye. This result also suggests that only a unitary accommodation response was generated in the two eyes.

\section{Nature of the binocular interactions}

The results obtained in these experiments indicate that when the accommodation system is presented with conflicting binocular cues in a dynamic situation, the consensual response results from some form of combination of the stimuli presented to each eye. We show in Appendix 1 that a simple dual inter-

Table 1. Summary of results at $0.2 \mathrm{~Hz}$

\begin{tabular}{|c|c|c|c|c|c|c|c|c|}
\hline \multirow[b]{2}{*}{ Condition } & \multicolumn{2}{|l|}{ CMB } & \multicolumn{2}{|l|}{ DIF } & \multicolumn{2}{|c|}{ Monkey M } & \multicolumn{2}{|c|}{ Monkey B } \\
\hline & Gain & Phase & Gain & Phase & Gain & Phase & Gain & Phase \\
\hline BINOC & $\begin{array}{c}0.54 \\
(0.03)\end{array}$ & $\begin{array}{c}-5.6 \\
(2.0)\end{array}$ & $\begin{array}{c}0.75 \\
(0.02)\end{array}$ & $\begin{array}{r}-2.0 \\
(1.0)\end{array}$ & $\begin{array}{c}0.83 \\
(0.02)\end{array}$ & $\begin{array}{c}0.0 \\
(0.4)\end{array}$ & $\begin{array}{c}0.79 \\
(0.02)\end{array}$ & $\begin{array}{c}1.0 \\
(1.0)\end{array}$ \\
\hline MONOC & $\begin{array}{c}0.53 \\
(0.01)\end{array}$ & $\begin{array}{r}-17.9 \\
(1.0)\end{array}$ & $\begin{array}{c}0.75 \\
(0.01)\end{array}$ & $\begin{array}{r}-18.6 \\
(0.9)\end{array}$ & $\begin{array}{c}0.72 \\
(0.02)\end{array}$ & $\begin{array}{c}-8.8 \\
(1.4)\end{array}$ & $\begin{array}{c}0.61 \\
(0.02)\end{array}$ & $\begin{array}{r}-29.5 \\
(1.5)\end{array}$ \\
\hline RA & $\begin{array}{c}0.38 \\
(0.01)\end{array}$ & $\begin{array}{r}-29.4 \\
(1.6)\end{array}$ & $\begin{array}{c}0.61 \\
(0.02)\end{array}$ & $\begin{array}{r}-18.7 \\
(1.3)\end{array}$ & $\begin{array}{c}0.28 \\
(0.01)\end{array}$ & $\begin{array}{r}-28.8 \\
(1.1)\end{array}$ & $\begin{array}{c}0.34 \\
(0.01)\end{array}$ & $\begin{array}{r}-30.0 \\
(2.1)\end{array}$ \\
\hline LAG & $\begin{array}{c}0.21 \\
(0.02)\end{array}$ & $\begin{array}{r}-53.4 \\
(4.0)\end{array}$ & $\begin{array}{c}0.21 \\
(0.01)\end{array}$ & $\begin{array}{r}-82.5 \\
(4.5)\end{array}$ & $\begin{array}{c}0.16 \\
(0.01)\end{array}$ & $\begin{array}{r}-70.7 \\
(3.0)\end{array}$ & $\begin{array}{c}0.25 \\
(0.01)\end{array}$ & $\begin{array}{r}-64.0 \\
(2.5)\end{array}$ \\
\hline ANISO & $\begin{array}{c}0.00 \\
(0.01)\end{array}$ & $\begin{array}{c}-10.3 \\
(67.6)\end{array}$ & $\begin{array}{c}0.03 \\
(0.01)\end{array}$ & $\begin{array}{c}66.0 \\
(16.5)\end{array}$ & $\begin{array}{c}0.06 \\
(0.01)\end{array}$ & $\begin{array}{c}-86.8 \\
(11.3)\end{array}$ & $\begin{array}{c}0.03 \\
(0.01)\end{array}$ & $\begin{array}{c}-34.2 \\
(22.2)\end{array}$ \\
\hline REYE & $\begin{array}{c}0.16 \\
(0.01)\end{array}$ & $\begin{array}{c}-5.6 \\
(3.4)\end{array}$ & $\begin{array}{c}0.22 \\
(0.01)\end{array}$ & $\begin{array}{r}-16.8 \\
(2.1)\end{array}$ & $\begin{array}{c}0.08 \\
(0.01)\end{array}$ & $\begin{array}{r}-14.5 \\
(8.3)\end{array}$ & $\begin{array}{c}0.19 \\
(0.01)\end{array}$ & $\begin{array}{r}-28.2 \\
(3.4)\end{array}$ \\
\hline LEYE & $\begin{array}{c}0.16 \\
(0.01)\end{array}$ & $\begin{array}{r}-20.0 \\
(3.6)\end{array}$ & $\begin{array}{c}0.11 \\
(0.01)\end{array}$ & $\begin{array}{r}-14.1 \\
(3.5)\end{array}$ & $\begin{array}{c}0.06 \\
(0.01)\end{array}$ & $\begin{array}{r}-44.3 \\
(9.9)\end{array}$ & $\begin{array}{c}0.24 \\
(0.01)\end{array}$ & $\begin{array}{r}-31.8 \\
(2.8)\end{array}$ \\
\hline
\end{tabular}




$\begin{array}{ll}\text { Conditions: } & \square \text { RA } \\ \text { - MONOC } & \text { - ANISO } \\ \text { O BINOC } & \diamond \text { LAG } \\ \Delta \text { LEYE } & \triangle \text { REYE }\end{array}$
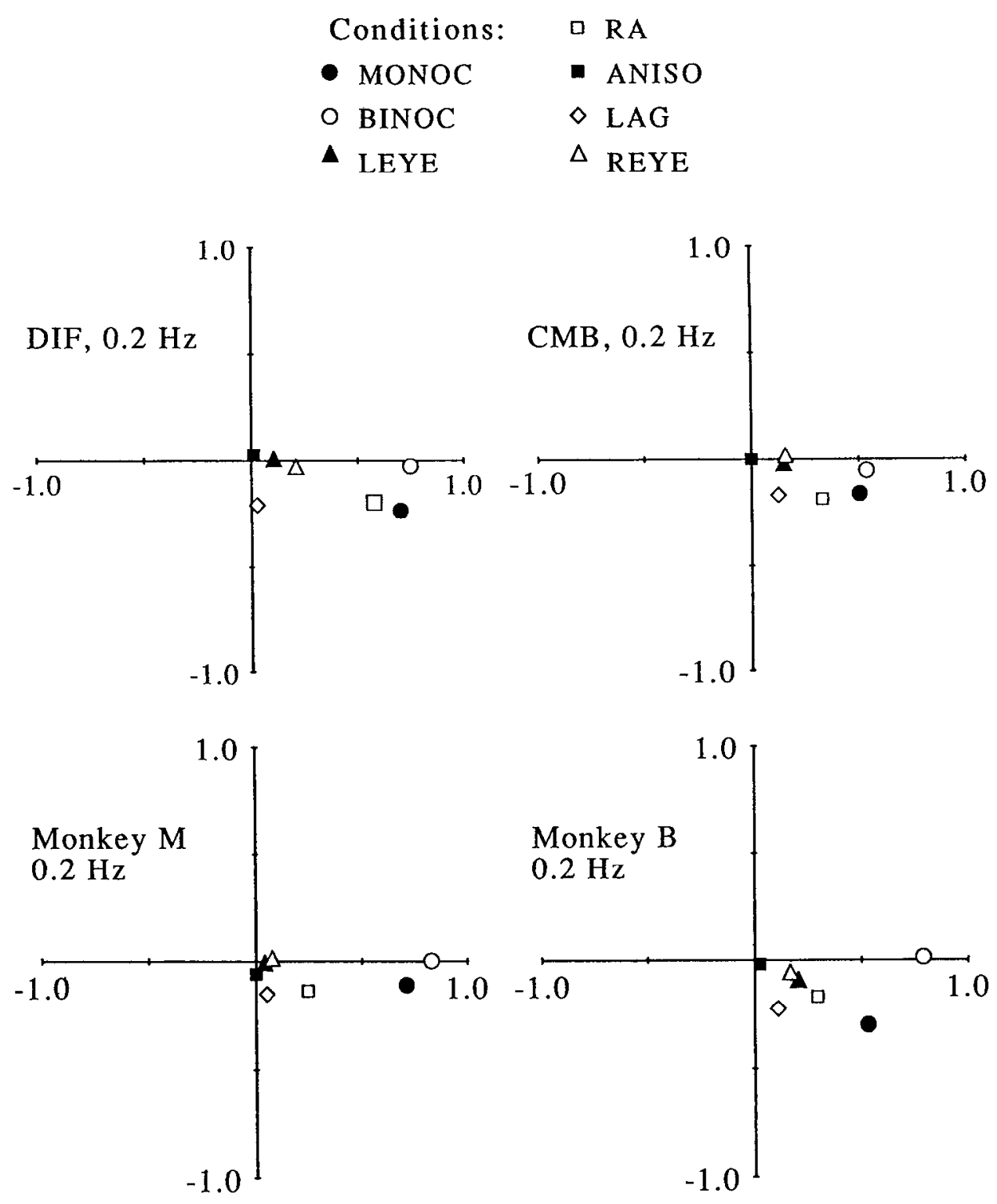

Figure 10. Nyquist representation of mean accommodation responses in subjects DIF, CMB, monkey $M$, and monkey $B$ under the different viewing conditions at $0.2 \mathrm{~Hz}$. The SEs associated with the gain and phase of each response are shown in Table 1 (note that the human data were obtained using the horizontal grating viewing target and the monkey data were obtained with the cross target). active control model of the near response (see Semmlow, 1981, for a review of this concept) leads to a prediction that the accommodation response to low-frequency sinusoidal stimuli should be well approximated by a weighted average of the responses generated by each of the components in isolation. If the weights attached to the left and right eye inputs and vergence in such a model are $A_{l}, A_{r}$, and $V$ and the vectors $\mathrm{l}, \mathbf{r}$ and $\mathbf{v}$ represent the accommodation responses that would be generated by, respectively, blur in the left eye alone, blur in the right eye alone, and vergence, then the response to all three stimuli in combination (a) will be given by

$$
\mathbf{a}=\frac{\left(A_{t} \mathbf{l}+A_{r} \mathbf{r}+V \mathbf{v}\right)}{\left(A_{i}+A_{r}+V\right)}
$$

In these experiments, the vergence stimulus was held constant (so-called relative accommodation); therefore, $\mathbf{v}$ has zero magnitude and Equation $\mathbf{l}$ reduces to $\mathbf{a}=\left(A_{l} \mathbf{l}+A_{r} \mathbf{r}\right) /\left(A_{l}+A_{r}+V\right)$. Note that this does not mean that vergence accommodation is being neglected. In relative accommodation, the amplitude of the anticipated accommodation response will be decreased from that expected by a simple average of the two monocular inputs by the term $V$ in the denominator, which reflects the contribution made by vergence accommodation. This factor $(\alpha)$ will be equal to $\left(A_{t}+A_{r}\right) /\left(A_{t}+A_{r}+V\right)$ and varies from 0 to 1 depending on the significance of vergence accommodation in a given individual. The relative weight given to the accommodation input from each eye can in turn be reduced to a single parameter $\beta$, which also varies from 0 to 1 and can be defined as $A_{l} /\left(A_{l}+A_{r}\right)$. This allows Equation 1 to be expressed as

$$
\mathbf{a}=\alpha(\beta \mathbf{1}+(1-\beta) \mathbf{r}) .
$$

This simple model allows predictions to be made of the accommodation response in each of the anisometropic conditions. In the ANISO condition the two monocular accommodation vectors are in opposite directions. This implies that in the case where the inputs from each eye are given equal weight (i.e., $\beta$ $=0.5$ ), there would be no modulated response. In the LAG condition, if $\beta=0.5$, then the phase lag of accommodation should be increased relative to that observed in the RA con- 
DIF $0.2 \mathrm{~Hz}$ LAG

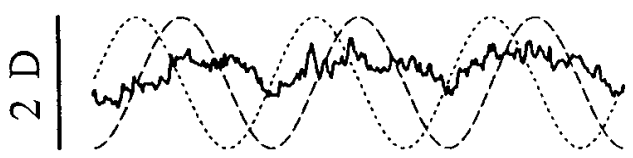

CMB $0.2 \mathrm{~Hz}$ LAG

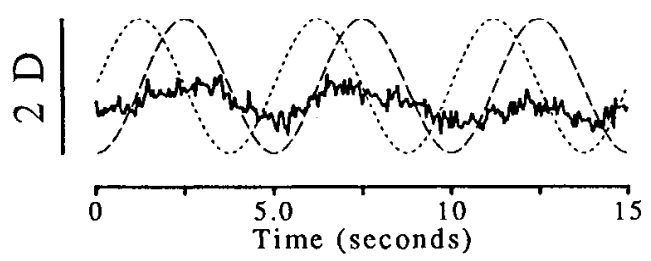

Monkey M $0.2 \mathrm{~Hz}$ LAG

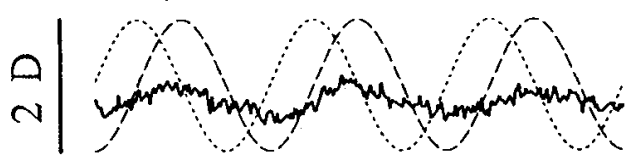

Monkey B $0.2 \mathrm{~Hz} \mathrm{LAG}$

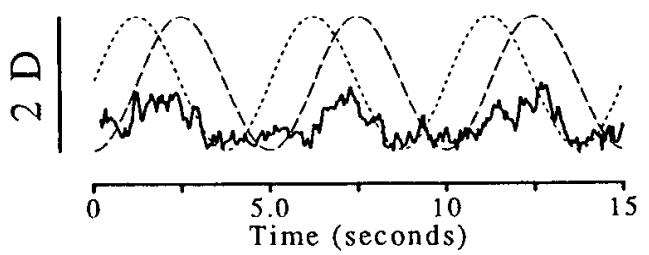

Figure 11. Examples of the accommodation responses of $\mathrm{CMB}, \mathrm{DIF}$, monkey $\mathrm{M}$, and monkey $\mathrm{B}$ in the LAG condition (dashed lines, right eye stimulus; dotted lines, left eye stimulus). dition by $45^{\circ}$. Provided anisometropia has no other effects on the relative importance of the different inputs, then the ratio of the gains in the RA and LAG conditions should be $1: \sqrt{2} / 2$. Similarly, in the LEYE and REYE conditions, the gains of the accommodation response, expressed as a ratio of the gain in RA condition viewing, should be $\beta$ and $1-\beta$, respectively, and the phase lag should be equal to that in the RA condition.

Figure 13 shows, in the form of Nyquist diagrams, estimates of the expected responses of the model (large symbols) calculated from Equation 2 for the four anisometropic conditions together with the observed responses (small symbols) at $0.2 \mathrm{~Hz}$. The gain and phase of accommodation in right eye monocular viewing were used to calculate the appropriate uniocular responses (l and $\mathbf{r}$ ).

The parameters $\alpha$ and $\beta$ were obtained by calculating the predicted a values for all possible combinations of $\alpha$ and $\beta$, calculating the magnitude of the error vectors (the vectors representing the difference between observed and predicted a values), and choosing the $\alpha$ and $\beta$ that gave the least square error. This may seem an involved procedure, but there is no clear alternative. Fquation 1 is linear, but the variables are two-di- mensional vectors, rather than scalars, and this makes standard linear regression methods impossible. Moreover, in Equation 2 the paramcters to bc cstimatcd ( $\alpha$ and $\beta$ ) are nonlinear functions of the known quantities, which makes more general linear leastsquares methods inapplicable.

The model provides a good description of the observed results under anisometropia both for human subjects and for monkey B. The fit for monkey $M$ is somewhat less precise. Of particular interest is that although the model can be successfully fit to the data, the best-fit estimates of $\alpha$ differ significantly from those obtained by calculating the ratio of the response gains in the RA and MONOC conditions (Table 2). There are also smaller differences between the value of $\beta$ obtained by the least-squares method and by consideration of the gains in the LEYE and REYE conditions; if $R$ represents the ratio of the accommodation response gain in the LEYE and REYE conditions, then $\beta=R /(1+R)$. The values of $\alpha$ obtained by fitting the model to the results obtained under anisometropic conditions are, for threc out of the four subjects, appreciably smaller than those predicted by consideration of the gain under normal relative accommodation (RA condition). This implies that the gain of

$\begin{array}{ll}\text { Conditions: } & \square \text { RA } \\ \text { - MONOC } & \approx \text { ANISO } \\ \text { - BINOC } & \diamond \text { LAG } \\ \text { A LEYE } & \triangle \text { REYE }\end{array}$

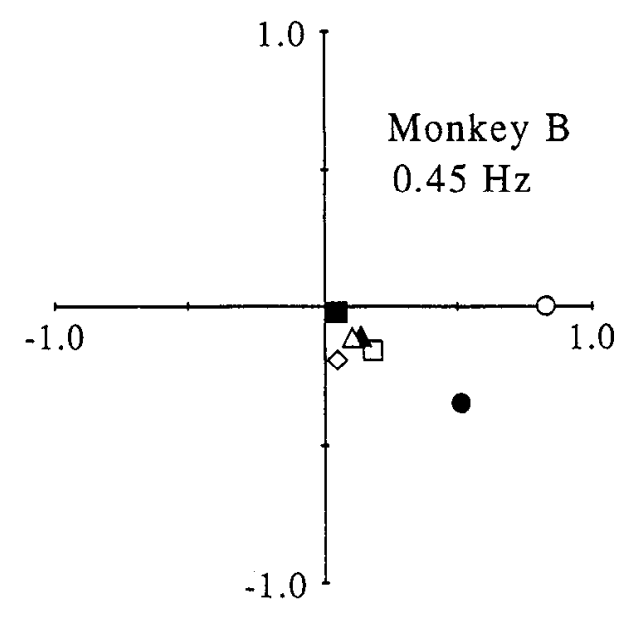

Figure 12. Nyquist diagram showing the mean accommodation responses of monkey $\mathrm{B}$ at $0.2 \mathrm{~Hz}$ and $0.45 \mathrm{~Hz}$ in all seven viewing conditions with the cross target. 

$\triangle$ REYE
- ANISO
A LEYE
$\diamond$ LAG

Large symbols $=$ Model Estimate, Small symbols = Mean Response
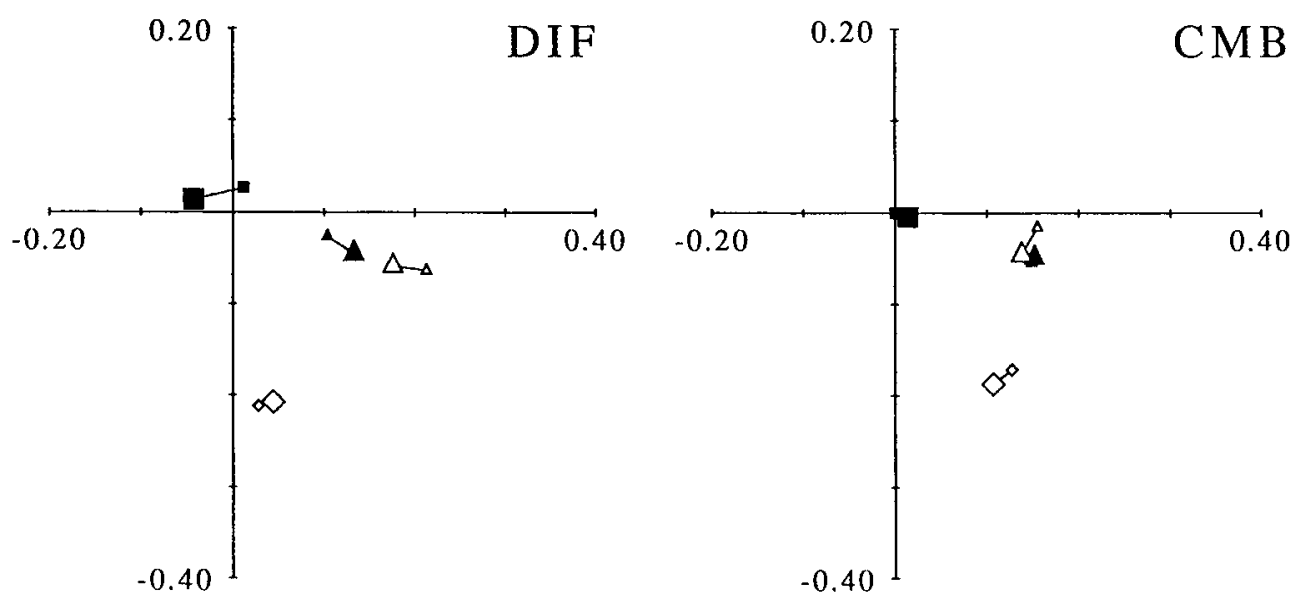

Figure 13. Nyquist plots comparing the mean observed accommodation responses obtained in the four anisometropic viewing conditions with the predictions of the model represented in Equation 2. In each case, the larger symbols represent the predicted response and the smaller symbols represent the mean observed response.
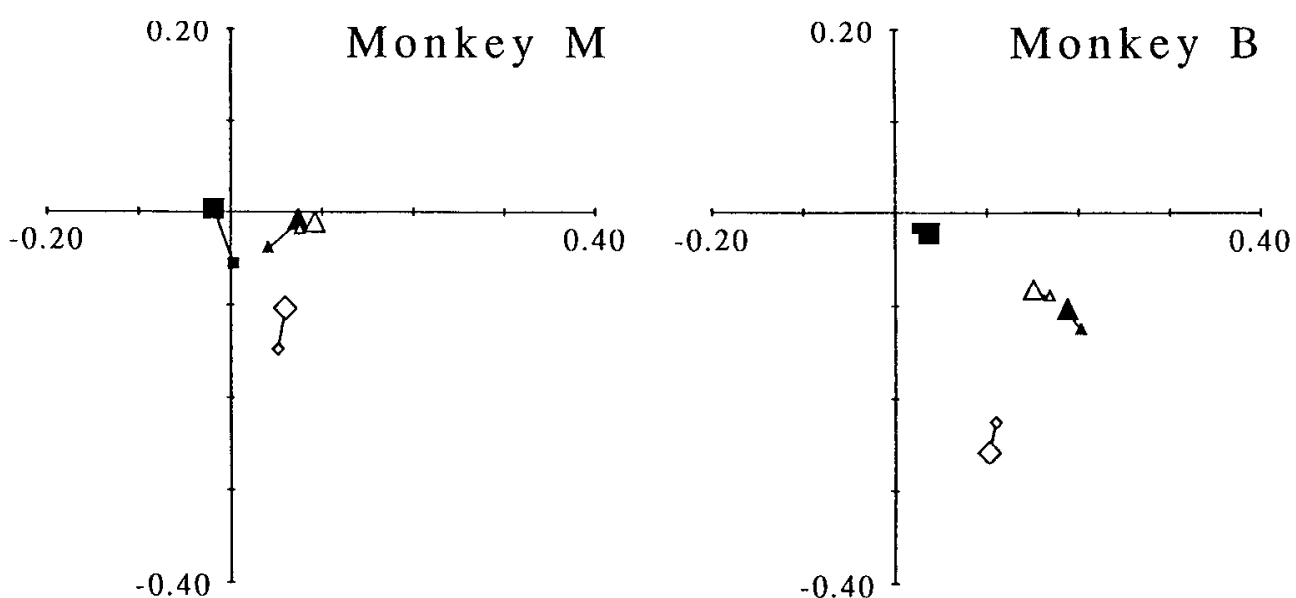

accommodation in the different forms of anisometropia was uniformly reduced when compared with the gains expected on the basis of non-anisometropic relative accommodation.

There are two possible explanations for the lower than expected gains observed when the two eyes are presented with conflicting accommodative stimuli. This observation might reflect some form of synergistic interaction that occurs when the accommodation system is presented with similar information in the two eyes that is lost with anisometropic stimulation. Alternatively, the reduction in response gain in anisometropia may represent some form of suppressive mechanism that is activated by interocular differences in image clarity. The existence of a mechanism for suppressing the input from one eye on the basis of differences in the quality of the two retinal images can be inferred from the association between naturally occurring anisometropia and amblyopia (Duke-Elder and Wybar, 1973). Although such a mechanism might be expected to operate over a very long time scale, there is evidence for such phenomena in acute experimental situations. Fiorentini et al. (1978) re- ported that the degree of binocular summation of the visual evoked potential for a 3 cycles/degree square-wave pattern was reduced when artificial anisometropia was induced with a trial lens; as the level of blur was increased, the binocular response declined at a faster rate than the monocular response.

Within this model, the only effect of opening the vergence loop (i.e., removing fusional cues) should be an increase in the value of $\alpha$, that is, a proportionately equivalent increase in the gains of the responses. Comparison of the least-squares estimate of $\alpha$ for the results obtained under anisometropic conditions from subjects DIF and CMB with the cross target (vergence loop closed) and grating target (reduced fusional cues, vergence loop partially opened) confirmed this prediction. Changing to the grating stimulus increased the best-fit value of $\alpha$ from 0.35 to 0.44 for subject DIF and from 0.52 to 0.57 for subject CMB.

The more general question is whether the accommodation responses were sufficiently diminished by the disparity-vergence loop remaining closed in the majority of experiments that significant accommodation responses would have been undetect- 
able. Careful consideration of the results shows that this was not the case. Table 1 shows that the standard errors on accommodation gain measurements were rarely more than $0.02 \mathrm{D}$ (since the modulation amplitude was $1 \mathrm{D}$, the gain figures can also be considered as response amplitude in diopters). Thus, an undetectable accommodation response could have had an amplitude of no more than $0.04 \mathrm{D}$. This is a very small variation. If we had used systematically a vergence open-loop condition, how much greater would the accommodation responses have been? The gains of relative accommodation were never less than 0.25 (with the vergence loop closed). Moreover, in three of the four subjects, accommodation gain in relative accommodation was more than $50 \%$ of that in monocular viewing. Thus, a twofold increase is probably realistic. However, let us make the generous assumption that in vergence open-loop viewing, the gain could in principle have been 1.0 , that is, up to fourfold greater than that in relative accommodation. Responses that had previously been undetectable at less than $0.04 \mathrm{D}$ would still have been less than $0.16 \mathrm{D}$ in amplitude-still a very small response indeed, in functional terms. For example, the usual figure for depth of focus under typical conditions is $\pm 0.25 \mathrm{D}$.

\section{Evidence for nonlinear binocular interactions}

Although a simple linear model appears to provide an adequate description of the responses to the four forms of anisometropia examined in this study, there is also evidence of nonlinearities within the mechanisms involved in binocular accommodation control. With a linear model, if the stimuli to the two eyes are sinusoidal, then the predicted response will also be sinusoidal. Equation 2 cannot, therefore, account for the presence of second harmonic components in the responses to counterphase, anisometropic stimulation (i.e., the ANISO condition).

The sccond harmonic component in the accommodation responses of monkey B in the ANISO condition displayed a consistent phase relationship with the sinusoidal modulations in accommodation demand. On this basis, it seems unlikely that the second harmonic component was the result of a process of random alternation. If the existence of a second harmonic component in the responses to counterphase anisometropic stimulation is indeed a binocular manifestation of the Mandelbaum effect, then the intersubject differences may derive from differences in the resting focus of accommodation. One would expect the second harmonic component to become more prominent when there is a substantial difference between the resting focus and the mean level of accommodation in the ANISO task. Such effects may also be more important in prolonged static anisometropia. Indeed, it has been found that in humans with hypermetropic anisometropia during childhood (i.e., with one normal and onc hypcrmetropic cyc), it is the hypcrmetropic cyc (the eye that would require a greater accommodative effort to obtain clear focus) that is most commonly amblyopic (DukeElder and Wybar, 1973).

Further evidence of nonlinear interactions can be derived by examining the phases of the accommodation responses under the various conditions examined in this study. For subject DIF and monkey $B$, both the gains and the phase lags of the accommodation responses could be accurately described by a linear model. For subject $\mathrm{CMB}$ and monkey $\mathrm{M}$, although the overall pattern of the results could be described by a linear model, there were differences in the phase lags of the responses in the MONOC, RA, REYE, and LEYE conditions that were not consistent with the operation of purely linear binocular interactions.

\begin{tabular}{|c|c|c|c|c|}
\hline \multirow[b]{2}{*}{ Subject } & \multicolumn{2}{|c|}{$\underline{\text { Best-fit values }}$} & \multicolumn{2}{|c|}{ Predicted values } \\
\hline & $\alpha$ & $\beta$ & $\bar{\alpha}$ & $\beta$ \\
\hline $\mathrm{CMB}$ & 0.57 & 0.52 & 0.71 & 0.51 \\
\hline DIF & 0.44 & 0.43 & 0.82 & 0.33 \\
\hline Monkey B & 0.64 & 0.56 & 0.56 & 0.56 \\
\hline Monkey M & 0.23 & 0.45 & 0.39 & 0.42 \\
\hline Mean & 0.47 & 0.49 & 0.62 & 0.45 \\
\hline
\end{tabular}

\section{Site of binocular interactions within the accommodation control system}

There are three basic hypotheses about the site within the accommodation pathways where the inputs from the two eyes are combined.

1. Sensory combination. The interaction may occur at a purely sensory level, creating a binocular representation of the retinal image prior to any analysis of the cues to accommodation.

2. Error combination. The signals from the two eyes may be combined after the extraction of an estimate of the defocus for each image, that is, at the stage of the error signal. ${ }^{2}$

3. Motor combination. The output may be generated by some of the output from two independent monocular control systems, that is, at the level of the motor response.

It is not possible to exclude any of the above general hypotheses on the basis of published data. However, one hypothesis, motor combination, the possibility that consensuality derives from an equal bilateral projection of the motor neurons of the Edinger-Wcstphal nucleus (as suggested by Ball, 1952), can be eliminated. Anatomical studies employing retrograde HRP tracing techniques have demonstrated that the ciliary body of each eye is innervated by separate motor neuron pools located in the ipsilateral Edinger-Westphal nucleus (Akert et al., 1980; Burde, 1980). This implies that at some stage prior to the motor neurons, a common accommodative pathway must exist that diverges to innervate the Edinger-Westphal neurons.

It is now generally accepted that different aspects of the visual image are processed in parallel by anatomically (or cytochemically) distinct pathways (Maunsell and Newsome, 1987). In both V1 and V2 there is a particularly striking separation of chromatic and luminance information (Livingstone and Hubel, 1984; De Yoe and Van Essen, 1985; Shipp and Zeki, 1985). Since both luminance and chromatic information are thought to be important in the control of accommodation, it is of some significance that there are differences in the binocular organization of the cells in these two pathways.

Within the luminance system, binocularity appears to be firmly established within the first few synapses of the visual cortex; outside the afferent input laminae of the striate cortex, the majority of cells can be driven by either eye (Hubel and Wiesel, 1977; Hawken and Parker, 1984). Thus, for accommodative cues related to achromatic image contrast, the binocular interactions may well take place before any error signal is generated. On this basis, the error signal would be obtained from a single

\footnotetext{
${ }^{2}$ Under control theory formulations of the accommodation system such as the Toates proportional control model (Toates, 1972), the error and the response cannot be properly considered as functionally distinct; the accommodation controller acts only as a gain element.
} 


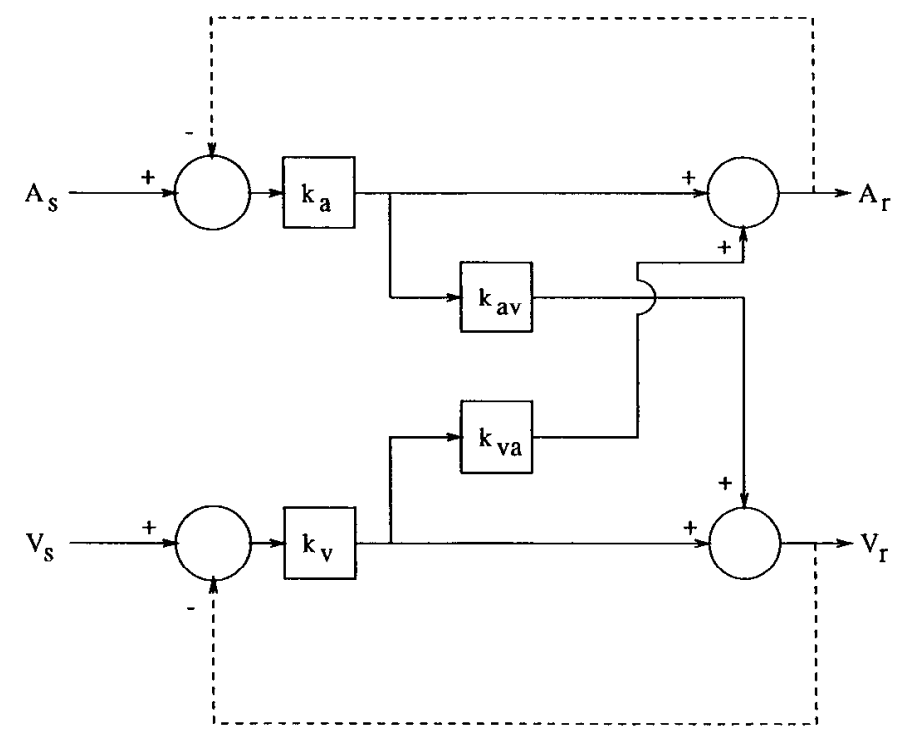

Figure 14. Dual interactive control model of the near response.

cyclopean representation of the information present on the retina of each eye. If this were so, then the consensual nature of accommodation would merely represent an inevitable consequence of the organization of low-level visual processing. In stark contrast with the luminance system, the low-level mechanisms thought to subserve color processing (located in the cytochrome oxidase "blobs") show little binocularity (Livingstone and Hubel, 1984). This paucity of binocular processing within the color pathways is supported by psychophysical studies that indicate that color information contributes little to the stereoscopic perception of depth (Livingstone and Hubel, 1987). The greater amount of monocular processing that occurs for chromatic information makes it possible that, for chromatic accommodative cues at least, the binocular interaction would take place with information more closely related to a uniocular accommodative error signal (Flitcroft, 1990).

The binocular interactions of the accommodative signals from each eye may thus not represent a unitary phenomenon. Indeed, it is possible that such binocular interactions occur at more than one location and that the nature of the interaction may be different at different sites. This would inevitably complicate the interpretation of the bchavioral cxpcriments described in this article. It is also possible that by adding or removing some of the various cues to accommodation, such as size change and chromatic aberration, the patterns of binocular interaction within the accommodation system may be subject to alteration.

\section{Comparison of binocular interactions in man and monkey}

In this study, we found litlle difference between the accommodation responses of the human and monkey subjects when presented with anisometropic stimuli. This finding is in keeping with previous studies that have demonstrated that the accommodation system in the rhesus monkey is very similar, and in some respects superior, to that found in man (Bito et al., 1982; Smith and Harwerth, 1984; Cumming and Judge, 1986).

Thus, the rhesus monkey appears to be an excellent experimental model for investigating the accommodation control system. It is particularly interesting that, in addition to the similarities in the normal operation of the accommodation reflex in man and monkey, there are also striking similarities between the two species in both the age-related alterations (Duane, 1912; Bito et al., 1982) of accommodative function and the impact of abnormalities such as amblyopia on accommodation (Wood and Tomlinson, 1975; Hokoda and Ciuffreda, 1982; Kiorpes and Boothe, 1984). These earlier findings together with results obtained in this study raise the hope that through investigations of the visual development of monkeys, it may be possible to define not only the physiological basis but also the etiology of many of the clinical abnormalities of binocular vision that are thought to result from optical and oculomotor deficits.

\section{Appendix: dual interactive control model predictions}

Consider the dual interactive controller scheme shown in Figure 14. The model consists of two interacting feedback loops, one (upper part of figure) driven by blur (defined as the difference between accommodation demand, $\mathbf{A}_{\mathbf{s}}$, and accommodation response, $\mathbf{A}_{\mathbf{r}}$ ), and the other (lower part of figure) driven by disparity (the difference between vergence demand, $\mathbf{V}_{s}$, and vergence response, $\mathbf{V}_{\mathrm{r}}$ ). The gain of the blur controller is $k_{\mathrm{a}}$, and the gain of the disparity controller is $\mathbf{k}_{\mathbf{v}}$. The two loops interact via the accommodative-vergence cross-link, which has gain $\mathbf{k}_{\mathbf{a v}}$, and the vergence-accommodation cross-link, which has gain $\mathbf{k}_{\mathbf{v}}$. Since we are concerned with dynamic sinusoidal stimulation, accommodation demand $\left(\mathbf{A}_{\mathrm{s}}\right)$ and response $\left(\mathbf{A}_{\mathrm{r}}\right)$, and vergence demand $\left(\mathbf{V}_{s}\right)$ and response $\left(\mathbf{V}_{r}\right)$ are numbers that are complex in the strict mathematical sense; that is, they have real and imaginary parts so that they can describe both the gain and phase of the stimuli and responses. Another way of expressing this is that the variables are vectors. Following the usual mathematical convention, such vector variables are depicted in boldface. The gains $\mathbf{k}_{\mathbf{a}}, \mathbf{k}_{\mathbf{v}}, \mathbf{k}_{\mathrm{av}}$, and $\mathbf{k}_{\mathrm{va}}$ are also complex variables.

Considering the signals in the accommodation loop,

$$
\mathbf{k}_{\mathbf{a}}\left(A_{\mathbf{s}}-A_{r}\right)+\mathbf{k}_{\mathbf{v}} \mathbf{k}_{\mathbf{v a}}\left(\mathbf{V}_{\mathbf{s}}-\mathbf{V}_{\mathbf{r}}\right)=\mathbf{A}_{\mathbf{r}} \text {. }
$$

In the vergence loop,

$$
\mathbf{k}_{\mathrm{v}}\left(\mathbf{V}_{\mathrm{s}}-\mathbf{V}_{\mathrm{r}}\right)+\mathbf{k}_{\mathrm{a}} \mathbf{k}_{\mathrm{av}}\left(\mathbf{A}_{\mathrm{s}}-\mathbf{A}_{\mathrm{r}}\right)=\mathbf{V}_{\mathrm{r}}
$$

By solving these two simultaneous equations, it can be shown that $A_{r}$ is related to $A_{s}$ and $V_{s}$ by

$$
A_{\mathbf{r}}=\frac{\left(\mathbf{g}_{\mathrm{a}}-\mathbf{g}_{\mathrm{av}} \mathbf{g}_{\mathrm{va}}\right) \mathbf{A}_{\mathrm{s}}+\mathbf{g}_{\mathrm{va}}\left(1-\mathbf{g}_{\mathrm{a}}\right) \mathbf{V}_{\mathrm{s}}}{\left(1-\mathbf{g}_{\mathrm{av}} \mathbf{g}_{\mathrm{va}}\right)}
$$

where

$$
\mathbf{g}_{\mathbf{a}}=\frac{\mathbf{k}_{\mathrm{a}}}{\mathbf{k}_{\mathbf{a}}+1}, \mathbf{g}_{\mathrm{v}}=\frac{\mathbf{k}_{\mathrm{v}}}{\mathbf{k}_{\mathrm{v}}+1}, \mathbf{g}_{\mathrm{av}}=\frac{\mathbf{k}_{\mathbf{a}} \mathbf{k}_{\mathbf{a v}}}{\mathbf{k}_{\mathbf{a}}+1} \text {, and } \mathbf{g}_{\mathrm{va}}=\frac{\mathbf{k}_{\mathrm{v}} \mathbf{k}_{\mathrm{va}}}{\mathbf{k}_{\mathrm{v}}+1}
$$

that is, the $\mathrm{g}$ values are the closed loop gains of accommodation, vergence, accommodative vergence, and vergence accommodation, respectively.

We wish to determine the nature of the relationship between the accommodation that is generated by blur alone, that generated by vergence (or disparity) alone, and that generated with the vergence stimulus held at a constant value (i.e., in relative accommodation). In the absence of disparity information (i.e., $\left.\mathbf{g}_{\mathrm{va}}=0\right)$,

$$
\mathbf{A}_{\mathbf{r}(\text { blur })}=\mathbf{g}_{\mathbf{a}} \mathbf{A}_{\mathbf{s}} \text {, }
$$

and in the absence of blur information (i.e., both $\mathbf{g}_{\mathrm{a}}$ and $\mathbf{g}_{\mathrm{ar}}=$ 0 ),

$$
\mathbf{A}_{\mathrm{r}(\text { vergence) }}=\mathbf{g}_{\mathrm{va}} \mathbf{V}_{\mathbf{s}} \text {. }
$$


In relative vergence, $\mathbf{V}_{\mathbf{s}}=0$ and so Equation $\mathrm{A} 3$ reduces to

$$
A_{r(R A)}=\frac{\left(g_{a}-g_{a r} g_{v a}\right) A_{s}}{\left(1-g_{a v} g_{v a}\right)} .
$$

What we have assumed in the weighted linear summation model for predicting the accommodation response in various conditions is that $\mathbf{A}_{\mathbf{r}(\mathbf{R A})}$ is a scalar linear function of $\mathbf{A}_{\mathrm{r}(\mathrm{bur})}$ and $\mathbf{A}_{\text {rvergence) }}$. As one can see from the above equations, this is not true in general, but it will be a good approximation if the closed loop gains $\mathbf{g}_{\mathrm{a}}, \mathbf{g}_{v}, \mathbf{g}_{\mathrm{a}}$, and $\mathbf{g}_{\mathrm{va}}$ are vectors with phase not too far from zero, because the coefficients of $A_{s}$ and $V_{s}$ in Equations A3-A6 will then collapse to scalar values. In these experiments, $\mathrm{g}_{\mathrm{a}}$ certainly had a phase within $30^{\circ}$ of zero at $0.2 \mathrm{~Hz}$ (see Table 1 , MONOC). While the other variables were not measured in the current experiments, previous experiments (e.g., Cumming and Judge, 1986) show that at frequencies of $0.2 \mathrm{~Hz}$, the phase lags of accommodation and vergence are small under all conditions, and this implies that the other variables have phases near zero.

\section{References}

Akert K, Glicksman MA, Lang W, Grob P, Huber A (1980) The Edinger-Westphal nucleus in the monkey: a retrograde tracer study. Brain Res 184:491-498.

Ball EAW (1952) A study in consensual accommodation. Am J Optom Arch Am Acad Optom 29:561-574.

Bito LZ, DeRousseau CJ, Kaufman PL, Bito JW (1982) Age dependent loss of accommodative amplitude in rhesus monkeys: an animal model for presbyopia. Invest Ophthalmol Vis Sci 23:23-31.

Breese BB (1909) Binocular rivalry. Psychol Rev 16:410-415.

Burde RM, Loewy AD (1980) Central origin of oculomotor parasympathetic neurones in the monkey. Brain Res 198:434-439.

Campbell FW (1960) Correlation of accommodation between the two eyes. J Opt Soc Am 50:738.

Chatfield C (1984) The analysis of time series: an introduction, 3d ed. London: Chapman and Hall.

Chin NB, Ishikawa S, Lappin H, Davidowitz J, Breinin GM (1968) Accommodation in monkeys induced by midbrain stimulation. Invest Ophthalmol 7:386-396.

Cumming BG, Judge SJ (1986) Disparity-induced and blur-induced convergence eye movement and accommodation in the monkey. $J$ Neurophysiol 55:896-914

De Yoe EA, Van Essen DC (1985) Segregation of afferent connections and receptive field properties in visual area V2 of the macaque. Nature 317:58-60.

Duane A (1912) Normal values of the accommodation at all ages. JAMA 59:1010-1013.

Duke-Elder WS, Wybar KC (1973) System of ophthalmology, Vol VI, Ocular motility and strabismus. London: Kimpton.

Fincham EF, Walton J (1957) The reciprocal actions of accommodation and vergence. J Physiol (Lond) 137:488-508.

Fiorentini A, Maffei L, Pirchio M, Spinelli D (1978) An electrophysiological correlate of perceptual suppression in anisometropia. Vision Res 18:1617-1621.

Flitcroft DI (1988) Binocular interactions and the accommodation reflex. Perception 17:349.

Flitcroft DI (1990) A neural and computational model for the chromatic control of accommodation. Vis Neurosci 5:547-555.

Flitcroft DI, Judge SJ (1989) Binocular interaction between stimuli to accommodation, studied in man and the rhesus monkey (Macaca mulatta). J Physiol (Lond) 413:37P.

Francis EL, Owens DA (1983) The accuracy of binocular vergence for peripheral stimuli. Vision Res 23:13-19.

Fuchs AF, Robinson DA (1966) A method for measuring horizontal and vertical eye movement chronically in the monkey.J Appl Physiol 21:1068-1070.
Hawken MJ, Parker AJ (1984) Contrast sensitivity and orientation selectivity in lamina IV of the striate cortex of old world monkeys. Exp Brain Res 54:367-372.

Hennessy RT, lida T, Shiina K, Leibowitz HW (1976) The effect of pupil size on accommodation. Vision Res 16:587-589.

Hokoda SC, Ciuffreda KJ (1982) Measurement of accommodative amplitude in amblyopia. Ophthalmol Physiol Opt 2:205-212.

Hubel DH, Wiesel TN (1977) Functional architecture of macaque monkey visual cortex. Proc R Soc Lond [Biol] 198:1-59.

Judge SJ, Richmond BS, Chu FC (1980) Implantation of magnetic search coils for measurement of eye position: an improved method. Vision Res 20:535-538.

Kiorpes L, Boothe RG (1984) Accommodative range in amblyopic monkeys (Macaca nemestrina). Vision Res 24:1829-1834.

Kruger PB, Pola J (1985) Changing size is a stimulus for accommodation. J Opt Soc Am A 75:1832-1835.

Leibowitz HW, Owens DA (1978) New evidence for the intermediate position of relaxed accommodation. Doc Ophthalmol 46:133-147.

Livingstone MS, Hubel DH (1984) Anatomy and physiology of a color system in the primate visual cortex. J Neurosci 4:309-356.

Livingstone MS, Hubel DH (1987) Psychophysical evidence for separate channels for the perception of form, color, movement, and depth. J Neurosci 7:3416-3468.

Mandelbaum J (1960) An accommodation phenomenon. Arch Ophthalmol 63:923-926.

Maunsell JHR, Newsome WT (1987) Visual processing in monkey extrastriate cortex. Annu Rev Neurosci 10:363-401.

Mordi J, Tucker J, Charman WN (1986) Effects of $0.1 \%$ cyclopentolate or $10 \%$ phenylephrine on pupil diameter and accommodation. Ophthalmol Physiol Opt 6:221-227.

Ogle KN (1937) Relative sizes of ocular images of the two eyes in asymmetric convergence. Arch Ophthalmol 22:1046-1066.

Ogle KN, Mussey F, Prangan SD (1949) Fixation disparity and the fusional processes in binocular single vision. Am J Ophthalmol 32: 1069-1087.

Owens DA (1979) The Mandelbaum effect: evidence for an accommodative bias towards intermediate viewing distances. J Opt Soc Am 69:646-652.

Robinson DA (1963) $\Lambda$ method of measuring eye movement using a scleral search coil in a magnetic field. IEEE Trans Biomed Eng 10: $137-145$

Rosenberg R, Flax N, Brodsky B, Abelman L (1953) Accommodation levels under conditions of asymmetric convergence. Am J Optom Arch Am Acad Optom 30:244-254.

Satra D, Otto J (1976) Objective measurement of consensual accommodation. Klin. Monatsbl Augenheilkd 168:87-89.

Schor CM (1983) Fixation disparity and vergence adaptation. In: Vergence eye movements: basic and chemical aspects (Schor CM, Ciuffreda KJ, eds), pp 647-670. Boston: Butterworths.

Semmlow JL. (1981) The oculomotor near response. In: Models of oculomotor behavior (Zuber B, ed), pp 161-191. New York: Chemical Rubber.

Shipp S, Zeki S (1985) Segregation of pathways leading from V2 to areas V4 and V5 of macaque monkey visual cortex. Nature 315:322325.

Smith EL, Harwerth RS (1984) Behavioural measurements of accommodative amplitude in rhesus monkeys. Vision Res 24:1821-1827.

Spencer RW, Wilson KW (1954) Accommodative response in asymmetric convergence. Am J Optom Arch Am Acad Optom 31:498505 .

Stoddard KB, Morgan MW (1942) Monocular accommodation. Am J Optom Arch Am Acad Optom 19:460-465.

Thorn F, Grennan M, Heath D (1983) Consensual accommodation. Curr Eye Res 3:711-716.

Toates FM (1972) Accommodation function of the human eye. Physiol Rev 52:828-863.

Winn B (1987) Studies in binocular accommodation. PhD thesis, Glasgow Institute of Technology.

Wood ICJ, Tomlinson A (1975) The accommodative response in amblyopia. Am J Optom Physiol Opt 52:243-247.

Wurtz RH (1969) Visual receptive fields of striate cortex neurons in awake monkeys. J Neurophysiol 32:727-742. 